INSTITUTO DE PESQUISA ENERGÉTICAS E NUCLEARES

Autarquia associada à Universidade de São Paulo

\title{
AVALIAÇÃO DOS EFEITOS COLATERAIS AGUDOS EM PACIENTES COM CÂNCER DE PRÓSTATA TRATADOS COM RADIOTERAPIA CONFORMACIONAL EM UM HOSPITAL NO LESTE DE MINAS
}

HIGOR SOUZA CARLECH

Dissertação apresentada como parte dos requisitos para obtenção do Grau de Mestre em Tecnologia Nuclear aplicações.

Orientadora:

Dra. Maria Elisa Chuery Martins Rostelato 


\title{
INSTITUTO DE PESQUISA ENERGÉTICAS E NUCLEARES
}

Autarquia associada à Universidade de São Paulo

\section{AVALIAÇÃO DOS EFEITOS COLATERAIS AGUDOS EM PACIENTES COM CÂNCER DE PRÓSTATA TRATADOS COM RADIOTERAPIA CONFORMACIONAL EM UM HOSPITAL NO LESTE DE MINAS}

\section{HIGOR SOUZA CARLECH}

\author{
Dissertação apresentada como parte \\ dos requisitos para obtenção do Grau de \\ Mestre em Tecnologia Nuclear - \\ aplicações. \\ Orientadora: \\ Dra. Maria Elisa Chuery Martins \\ Rostelato
}

\section{Versão Corrigida}

Versão original disponível no IPEN 
Autorizo a reprodução e divulgação total ou parcial deste trabalho, para fins de estudo e pesquisa, desde que citada a fonte

Como citar:

CARLECH, H. S. Avaliação dos efeitos colaterais agudos em pacientes com câncer de próstata tratados com radioterapia conformacional em um Hospital no Leste de Minas. 2019. 49 p. Dissertação (Mestrado em Tecnologia Nuclear), Instituto de Pesquisas Energéticas e Nucleares, IPEN-CNEN/SP, São Paulo. Disponível em: (data de consulta no formato: dd/mm/aaaa)

Ficha catalográfica elaborada pelo Sistema de geração automática da Biblioteca IPEN/USP, com os dados fornecidos pelo(a) autor(a)

Carlech, Higor Souza

Avaliação dos efeitos colaterais agudos em pacientes com câncer de próstata tratados com radioterapia conformacional em um Hospital no Leste de Minas / Higor Souza Carlech; orientadora Maria Elisa Chuery Martins Rostelato. -- São Paulo, 2019. $49 \mathrm{p}$.

Dissertação (Mestrado) - Programa de Pós-Graduação em Tecnologia Nuclear (Reatores) -- Instituto de Pesquisas Energéticas e Nucleares, São Paulo, 2019.

1.Câncer de próstata. 2. Radioterapia Conformacional. 3. Toxicidade Aguda.. I. Rostelato, Maria Elisa Chuery Martins. orient. II. Título 


\section{AGRADECIMENTOS}

Ao Deus criador da vida por ter me dado forças para alcançar esse objetivo.

A orientadora Dra. Maria Elisa Chuery Martins Rostelato pela oportunidade, apoio e compreensão para o desenvolvimento deste trabalho.

A minha esposa Amanda e filhos João Pedro e Hannah pela compreensão e apoio.

A minha amiga Ana Carolina Lisboa, por toda instrução.

Ao Instituto de Pesquisas Energéticas e Nucleares (IPEN).

A Universidade do Vale do Aço (UNIVAÇO) pela oportunidade e investimento.

Ao Centro de Oncologia Integrada (COI) do Hospital Márcio Cunha por permitir a realização das pesquisas.

A todos os pacientes que fizeram parte dessa pesquisa. 


\section{RESUMO}

CARLECH, H. S. Avaliação dos efeitos colaterais agudos em pacientes com câncer de próstata tratados com radioterapia conformacional em um Hospital no Leste de Minas. 2019. 49p. Dissertação (Mestrado em Tecnologia Nuclear), Instituto de Pesquisas Energéticas e Nucleares, IPEN-CNEN/SP, São Paulo.

A radioterapia é frequentemente associada a uma ampla gama de efeitos adversos (EA) significativos. Esses EA são geralmente classificados como agudos ou tardios. Este estudo teve como objetivo avaliar a toxicidade aguda em pacientes com câncer de próstata tratados com radioterapia conformacional (IMRT)I na Unidade de Oncologia do Hospital Márcio Cunha, no Leste de Minas Gerais. A metodologia utilizada foi um estudo de coorte prospectivo, observacional, realizado através de uma amostra não probabilística de conveniência, totalizando 45 pacientes. Os pacientes incluídos no estudo foram acompanhados desde o início do tratamento até 3 meses após a radioterapia conformacional (IMRT). A observação mais frequente foi de pelo menos um EA agudo por paciente e o menos comum foi a manifestação de quatro EA concomitantemente. Nenhum paciente nesse estudo apresentou mais de quatro efeitos adversos agudos. Com o conhecimento da epidemiologia destes EA melhorou a instrumentalização do médico e paciente para escolher a modalidade terapêutica mais adequada para cada caso.

Palavras-chaves: Câncer de próstata. Radioterapia Conformacional (IMRT). Efeitos Adversos. Toxicidade Aguda. 


\begin{abstract}
CARLECH, H. S. Evaluation of acute side effects in prostate cancer patients treated with conformational radiotherapyratados in a hospital in eastern Minas Gerais. 2019. 49 p. Dissertação (Mestrado em Tecnologia Nuclear), Instituto de Pesquisas Energéticas e Nucleares, IPEN-CNEN/SP, São Paulo.
\end{abstract}

Radiatiotherapy is often associated with a wide range of significant adverse effects (AEs). These AEs are commonly classified as acute or delayed. This study aimed to evaluate acute toxicity in patients with prostate cancer treated with conformational radiotherapy (IMRT) in an Oncology Unit in Eastern Minas Gerais. The Methodology used was a prospective, observational cohort study, carried out using a nonprobabilistic convenience sample, totaling 45 patients. The Patients included in the study were followed from the start of treatment to 3 months after conformational radiotherapy (IMRT). The most frequent observation was at least one acute AE per patient and the least common was the manifestation of four AEs concomitantly. No patient in this study had more than four acute adverse effects. With the knowledge of the epidemiology of these $A E$, the instrumentalization of the doctor and patient improved to choose the most appropriate therapeutic modality for each case.

Keywords: Prostate Cancer. Conformational Radiotherapy (IMRT). Adverse Effects. Acute Toxicity. 


\section{SUMÁRIO}

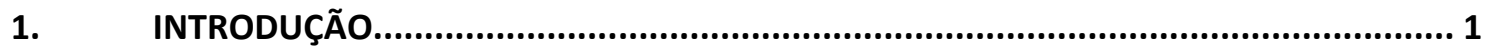

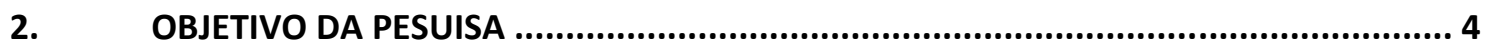

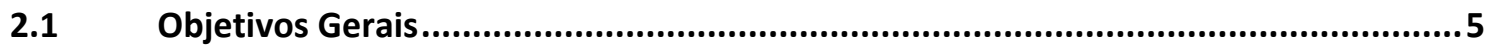

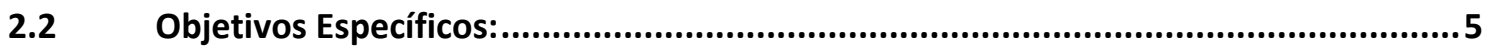

3 REVISÃO DA LITERATURA

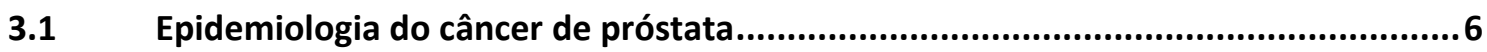

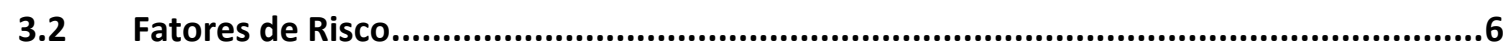

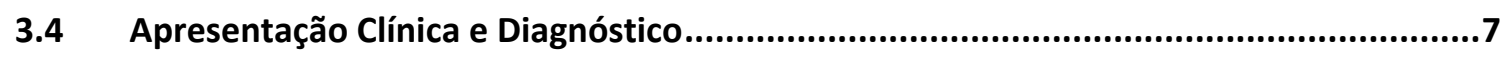

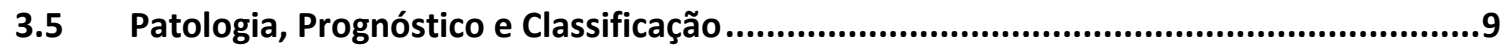

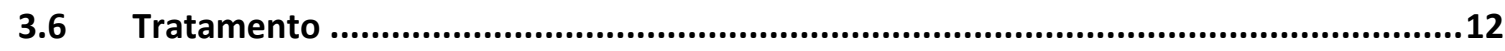

3.6.1 Radioterapia para tratamento de câncer de prostata .................................................13

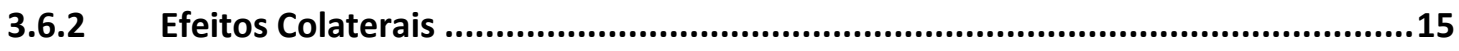

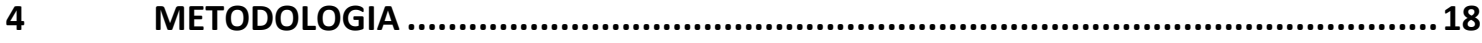

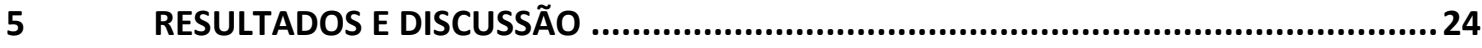

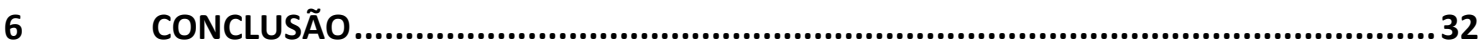

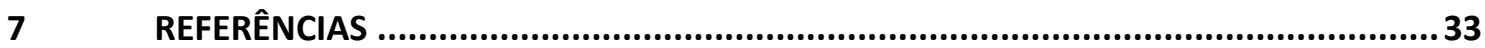

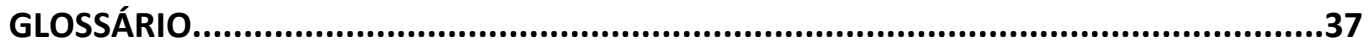

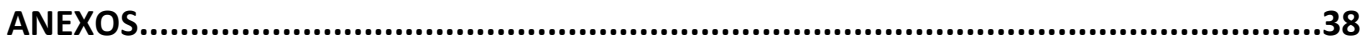




\section{INTRODUÇÃO}

O câncer de próstata (CAP) é o mais comum em homens brasileiros, com 68.220 novos casos em 2018, uma incidência de 66,82 novos casos por 100.000 (INCA, 2019). As taxas de incidência aumentadas ao longo dos anos devem-se à extensão da expectativa de vida associada à melhoria dos métodos de diagnóstico e à melhoria da qualidade dos sistemas de informação, além da ocorrência de sobrediagnóstico (AGENCIA SAÚDE, 2015).

A idade é o fator de risco mais relevante para o desenvolvimento da doença, seguido por região geográfica, etnia, histórico familiar e dieta. Cerca de $85 \%$ dos casos diagnosticados são em pacientes com mais de 65 anos (ANDERSON-JACKSON, L. et al., 2012), pessoas negras têm duas vezes mais risco de câncer de próstata do que pessoas brancas. A região geográfica e a etnia podem ser devidas aos hábitos alimentares, uma vez que foi comprovado que o alto consumo de gorduras insaturadas e o alto índice de massa corpórea aumentam o risco de doença. Além disso, a baixa ingestão de carboidratos associada à alta ingestão de ômega-3, chá verde, tomate e seus derivados não apenas mostra benefícios na redução do risco, mas também na progressão da doença (BARQAWI, A. B. et al., 2011)

As opções terapêuticas atuais do tratamento do câncer de próstata são: prostatectomia radical (BOORJIAN, S. A. et al., 2011) e radioterapia (RT) em duas modalidades: externa - radioterapia guiada por imagem (IGRT) e radioterapia com intensidade modulada (IMRT); e a interna também conhecida como braquiterapia. Outras opções de tratamento estão em uso, como braquiterapia de baixa dose, braquiterapia de alta dose, crioterapia, ultrassom focado em alta intensidade, radiocirurgia estereotáxica, terapia de prótons, íons de carbono (Cancer Research UK, 2015).

A prostatectomia é um procedimento cirúrgico que consiste na retirada da próstata e alguns dos tecidos à sua volta, incluindo vesículas seminais. $\mathrm{O}$ tratamento cirúrgico necessita de internação hospitalar, exames pré-operatórios, risco cirúrgico e ou risco anestésico. As vantagens da cirurgia são: menor taxa de recorrência da doença, possibilidade de análise das características patológicas da 
próstata uma vez que a glândula é retirada e analisada com maior detalhe e possibilidade do tratamento com radioterapia complementar caso haja recorrência da doença. Os riscos cirúrgicos mais comuns do intra-operatório e pós-operatório imediato são: reações a anestesia, hemorragias, lesões em órgãos próximos a próstata, infecção na ferida operatória, embolia pulmonar. Os riscos cirúrgicos do pós-operatório tardio são: incontinência urinária, impotência (disfunção erétil), alterações no orgasmo, alteração no tamanho do pênis, hérnia inguinal. (AMERICAN CANCER SOCIETY).

Atualmente a radioterapia por feixe externo (EBRT) e a braquiterapia (BT) são as mais aplicadas como terapias potencialmente curativas para o câncer de próstata. Nas últimas décadas a RT sofreu importante melhorias relacionadas à maior entrega de radiação com menor incidência em tecidos saudáveis. O aumento da dose na EBRT leva a um melhor controle locorregional da doença, maior sobrevida livre de recidiva bioquímica, maior sobrevida livre de metástases à distância, e até maior sobrevida global em pacientes com CAP classificados com risco intermediário e alto (HOFFMAN, R. M. et al., 2013). No entanto, o aumento da dose é limitado pela toxicidade nos tecidos saudáveis circundantes e, portanto, para se obter uma maior incidência de dose de radiação no tumor aumenta-se o risco de levar a uma maior toxicidade do tratamento, impactando bastante a qualidade de vida dos pacientes (INCA, 2015). Entretanto, desenvolveram-se tecnologias que permitem o aumento da dose por meio de planejamentos sofisticados de tratamento baseado em tecnologia computadorizada (EBRT) e/ou por meio de dispositivos como as sementes na braquiterapia, evitando o excesso de irradiação nos tecidos saudáveis circundantes. (LIN, P.-H.; ARONSON, W.; FREEDLAND, S. J. Nutrition, dietary interventions and prostate cancer: the latest evidence. BMC Medicine, v. 13, n. 1, p. 3, 2015)

Deve-se considerar que a próstata é um órgão móvel; portanto, têm que ser adicionadas margens ao redor do alvo durante o planejamento de EBRT (LUO, H.-C. et al., 2013). Com a limitação de aumentar a dose usando radioterapia conformacional em 3D (3DCRT), foram desenvolvidas a radioterapia guiada por imagem (IGRT) e a radioterapia com intensidade modulada (IMRT) as quais fornecem irradiação precisa e permitem o aumento da dose na próstata sem, contudo, aumentar a dose nos tecidos normais. Vários estudos têm demonstrado bons resultados para o tratamento do CAP com IMRT (MOON, S. J. et al., 2010). 
As vantagens da IMRT é não necessitar de internação hospitalar, durabilidade de poucos minutos de cada seção, recuperação física mais rápida e por se tratar de um procedimento não invasivo é indolor. Uma das desvantagens da IMRT é o longo tempo do tratamento: geralmente leva-se de 8 a 9 semanas para concluir o tratamento, um período bem mais longo do que o tratamento cirúrgico (prostatectomia) ou com radioterapia localizada (braquiterapia) (MILECKI, T. et al., 2014).

Em casos de câncer de próstata localmente avançado, a minimização dos efeitos colaterais é o fator mais importante a ser avaliado. A incontinência urinária, a urgência urinária e a disfunção erétil foram os efeitos colaterais mais frequentes após o tratamento com radioterapia (NATIONAL CANCER INSTITUTE, 2015). Os efeitos colaterais agudos são aqueles que ocorrem dentro de alguns dias ou semanas do início do tratamento até 90 dias. São normalmente monitorados, bem tolerados e reversíveis. Os mais comuns e muito menos apresentados em pesquisas científicas são na pele, como secura, coceira, bolhas ou descamação e aqueles relacionados à fadiga, falta de energia que não melhora com o descanso (PATE; KLEIN, 2015).

Os eventos tardios após 90 dias do início do tratamento podem chegar a 5 anos. Eles são mais raros, mas podem ser mais frequentes quando a dose de radiação nos tecidos é excedida. Eles se manifestam por atrofias, fibroses e inflamações, uma vez que as alterações genéticas e a formação de novos tumores são muito raras (PEREZ; BRADY'S, 2013)

A maioria das pesquisas científicas sobre câncer aponta para os benefícios da técnica IMRT no tratamento de tumores de próstata que promovem uma melhor qualidade de vida com menos efeitos colaterais. No entanto, o aumento constante no uso dessa técnica requer estudos independentes e individualizados, de acordo com as especificidades de cada centro de radioterapia e suas realidades socioeconômicas, para avaliar a viabilidade da implementação do IMRT. A redução dos efeitos colaterais do EBRT pode contribuir para a redução de custos e justificar a orientação das agências de financiamento de políticas públicas de saúde sobre a atualização do câncer.

Por isso, este trabalho teve como objetivo avaliar a toxicidade aguda em pacientes com câncer de próstata tratados com radioterapia conformacional na Unidade de Oncologia do Hospital Márcio Cunha, no Leste de Minas Gerais. 
A realização deste trabalho justifica-se pela necessidade de conhecer as manifestações das toxicidades agudas nos pacientes dentro da realidade socioeconômica da macrorregião assistida por essa Unidade de Oncologia. Desta forma, este estudo irá permitir uma divulgação junto à equipe dessa unidade acerca dos eventos adversos (EA) mais frequentes para que a mesma procure melhor conduzir esses pacientes minimizando o impacto na sua qualidade de vida. Ademais, conhecer a epidemiologia desses EA irá melhor instrumentalizar médico e paciente para escolher a sua modalidade terapêutica considerando as opções: prostatectomia, braquiterapia, radioterapia não conformacionada e EBRT. 


\section{OBJETIVO DA PESQUISA}

\subsection{Objetivos Gerais}

Avaliar a toxicidade aguda em pacientes com câncer de próstata tratados com radioterapia conformacional na Unidade de Oncologia do Hospital Márcio Cunha no Leste de Minas.

\subsection{Objetivos Específicos:}

- Traçar o perfil clínico dos pacientes com câncer de próstata que iniciaram o tratamento com radioterapia no período de setembro de 2016 a setembro de 2017.

- Acompanhar os pacientes incluídos no estudo durante o período de 3 meses com respeito a manifestações de efeitos colaterais agudos à radioterapia.

- Correlacionar os efeitos colaterais com o perfil clínico de cada paciente.

- Comparar os resultados obtidos com dados da literatura acerca dos efeitos colaterais agudos esperados. 


\section{REVISÃO DA LITERATURA}

\subsection{Epidemiologia do câncer de próstata}

O câncer de próstata (CAP) é o câncer mais comum em homens brasileiros, com 68.220 novos casos em 2018, uma incidência de 66,82 novos casos por 100.000 (INCA, 2019). As taxas de incidência aumentadas ao longo dos anos devem-se à extensão da expectativa de vida associada à melhoria dos métodos de diagnóstico e à melhoria da qualidade dos sistemas de informação, além da ocorrência de sobrediagnóstico (AGENCIA SAÚDE, 2015).

No Brasil, atribui-se o aumento das taxas de incidência ao longo dos anos ao aumento da expectativa de vida associada à melhoria e à evolução dos métodos diagnósticos e da qualidade dos sistemas de informação do país, bem como com a ocorrência de sobrediagnóstico (INCA, 2019).

A prevalência do câncer de próstata deve aumentar ao longo dos anos, mesmo com a tendência estática nas taxas de incidência. O número de sobreviventes de câncer de próstata é estimado para 831 mil até o ano de 2040 com um aumento médio anual de 5\% entre 2010 e 2020 no Reino Unido. Entre os 21 cânceres mais comuns o câncer de próstata apresenta-se em terceiro lugar com melhor taxa de sobrevida no Reino Unido (Cancer Research UK, 2015).

\subsection{Fatores de Risco}

Entre os fatores de riscos para o desenvolvimento da doença, a idade é o mais relevante, estando também presentes: geografia, etnia, histórico familiar e dieta. Aproximadamente $85 \%$ dos casos diagnosticados são em pacientes acima de 65 anos (PATE; KLEIN, 2009), o câncer de próstata é duas vezes mais comum em homens negros quando comparado com pessoas de pele branca (INCA, 2015). Os riscos associados à geografia e à etnia podem ser em decorrência dos hábitos alimentares inerentes a esses grupos, uma vez que já foi comprovado que, a ingestão elevada de gorduras insaturadas e um alto índice de massa corpórea, aumentam o risco de desenvolver a doença. Assim como, a baixa ingestão de carboidratos associada com a ingestão de ômega-3, chás verdes, tomates e seus 
derivados, não só mostra benefício na redução do risco, como para a progressão da doença (LIN; ARONSON; FREEDLAND, 2015). Também é importante destacar que vasectomia e doenças sexualmente transmissíveis não se apresentam como fatores de risco, enquanto o uso de cigarro e de andrógenos ainda se apresentam com dados inconclusivos acerca da sua correlação (MATSUDA; MATSUDA, 2011).

\subsection{Mortalidade}

O câncer de próstata ficou em segundo lugar como causa de morte por cânceres em homens, sendo responsável por mais de 30.000 mortes nos EUA. Dados recentes da OMS relatam que a taxa de mortalidade para esse câncer é comum em todos os países (INCA, 2015).

As taxas de mortalidade em todo o mundo para o câncer de próstata têm apresentado uma tendência de queda desde 1990, de cerca de $24 \%$ nos EUA e de 2-4\% em alguns países da Europa Ocidental, incluindo o Reino Unido, Áustria, França e Alemanha (HOFFMAN et al., 2013; MATSUDA; MATSUDA, 2011). No Brasil essa taxa se mantém estável de 12,4 a cada 100 mil, em 2002, para 13,65, em 2012 (AGENCIA SAÚDE, 2015). Em Minas Gerais as taxas de mortalidade bruta, padronizadas pela população mundial e pela brasileira, estimadas em 1999, foram de 7,95; 10,87 e 8,75 a cada 100 mil homens, respectivamente (INCA,2015).

\subsection{Apresentação Clínica e Diagnóstico}

Os doentes com câncer de próstata localizado, frequentemente são assintomáticos; o diagnóstico é muitas vezes feito através da dosagem do antígeno prostático específico (PSA). Na era pré PSA, os pacientes assintomáticos eram diagnosticados com base no toque retal (TR). Já os pacientes com tumores localmente avançados apresentam sintomas obstrutivos da bexiga, como hesitação urinária e diminuição da força do jato urinário. Obstrução crônica e distensão da bexiga podem conduzir a uma diminuição da conformidade do músculo detrusor, que se manifesta por sintomas de frequência urinária, urgência urinária e noctúria. Muitos doentes em estágio inicial ( $T 1 \mathrm{a}$ ou T1b) podem ocasionalmente ser diagnosticados através de uma Ressecção Transuretral da Próstata (RTU) com 
sintomas de obstrução da saída da bexiga causada por hiperplasia benigna da próstata. Com a invasão local para os dutos ejaculatórios ou uretra, os doentes podem apresentar hematúria ou hematospermia. À medida que a doença penetra na cápsula da próstata, pode haver invasão nos feixes neurovasculares que conduzem a uma disfunção erétil. Quando a doença está disseminada frequentemente se manifesta como dor óssea das metástases ósseas distantes (PEREZ; BRADY'S, 2013).

Atualmente a história clínica completa e um exame físico geral, incluindo TR são obrigatórios. O examinador do TR deve observar o tamanho da glândula, a sua coerência global e a presença de todas as áreas firmes. Um nódulo neoplásico típico de carcinoma prostático é extremamente firme, muitas vezes não é elevado acima da superfície da glândula, mas rodeado por tecido prostático compressível. O examinador deve determinar se os sulcos laterais são envolvidos por tumor e também o grau de propagação superior. Na maioria dos pacientes as vesículas seminais não podem ser palpadas como estruturas discretas, e a descoberta de uma área firme que se estende acima da próstata sugere que as vesículas seminais estão envolvidas por malignidade. Para se estabelecer um diagnóstico patológico se faz necessária uma biópsia, combinando os resultados do TR com PSA. A biópsia guiada por agulha (BGP) é o método mais comum de obtenção de amostras representativas do tecido prostático (PEREZ; BRADY'S, 2013).

Uma vez que o diagnóstico do tecido de câncer de próstata é determinado, o paciente deve passar por exames laboratoriais, como valor basal de PSA, hemograma completo e nível de testosterona. A radiografia de tórax deve ser realizada como parte do estadiamento inicial, apenas em casos de suspeita de doença metastática. 


\subsection{Patologia, Prognóstico e Classificação}

A próstata conforme ilustrada abaixo na Figura 1 é uma glândula localizada na pelve, adjacente ao reto, bexiga, dorsal e ao complexo venoso periprostático e musculatura pélvica da parede lateral, plexo pélvico e nervos cavernosos. A inervação da próstata é derivada do plexo prostático e seu suprimento arterial a partir dos ramos da artéria ilíaca interna. A drenagem linfática da glândula da próstata ocorre predominantemente através da ilíaca interna. A próstata envolve um segmento da uretra antes de passar pelo diafragma geniturinário. Histologicamente a próstata é composta por glândulas tubuloalveolares. As glândulas estão incorporadas em tecido conjuntivo de colágeno e de músculo liso constituindo o estroma prostático. Este estroma possui funções fibromusculares de controlar a micção, agindo como um esfíncter da uretra e de promover uma secreção ácida pela uretra durante a ejaculação através da contratação. A principal função da próstata é a produção de fluido seminal, que protege e alimenta o esperma após a ejaculação. A próstata contribui aproximadamente com $30 \%$ do fluido seminal, e as vesículas seminais, testículos e glândulas bulbouretrais fornecem os 70\% restantes (PEREZ; BRADY'S, 2013).

Figura 1 - Próstata

Fonte: http://www.mdsaude.com/

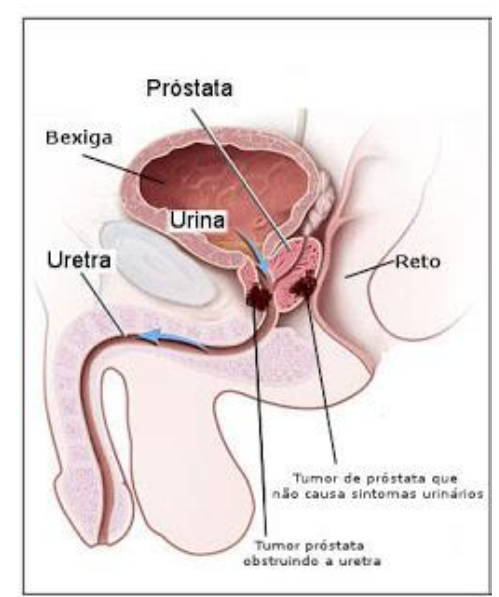

O tumor mais comum no câncer de próstata é o adenocarcinoma, de acordo com as características celulares ele é graduado em moderadamente ou pobremente diferenciado. Para essa avaliação levam-se em consideração: conteúdo nuclear, pleomorfismo, formação de glândula e invasão do estroma 
(D’AMICO et al., 1998). Os outros subtipos histológicos descritos na literatura são raros e com características clinicopatológicas diferentes do adenocarcinoma, a citar: carcinoma de ducto periureteral, adenocarcinoma ductal, tumor neuroendócrino, carcinoma mucinoso, carcinoma sarcomatóide, tumor endometrioide, carcinoma adenoide cístico, sarcoma, carcinosarcoma e linfoma primário (D'AMICO et al., 1998).

Desde a década de 70 vem sendo apresentado um sistema de classificação de escore de Gleason com o intuito de prever a evolução clínica dos pacientes e personalizar as estratégias de tratamento para o câncer de próstata. Esse sistema vem sofrendo alterações e adequações e hoje se definiu que apenas as características patológicas seriam consideradas, resultando na pontuação de Gleason que se apresenta em nove contagens discretas (variando entre 2 e 10). A pontuação de Gleason é um dos fortes preditores de comportamento biológico no câncer de próstata, incluindo capacidade de invasão e ocorrência de metástases. No entanto, esta técnica é limitada pela sua subjetividade no que diz respeito à capacidade do observador, por erros de amostragem, quando a biópsia não representa o subtipo histológico real ou o grau de diferenciação do tumor e também por laudos errôneos pelos patologistas (BARQAWI et al., 2011; D'AMICO et al., 1998). Barqawi et al. (2011) através do estudo que avalia a relevância em se obter uma segunda opinião sobre o laudo do patologista apresentaram uma discrepância estatisticamente significativa nos diagnósticos de 100 pacientes submetidos a uma prostatectomia radical, ressaltando a importância de uma reavaliação por um segundo patologista previamente à definição do tratamento proposto.

$O$ estadiamento do câncer de próstata também evoluiu com o advento e aprimoramento das técnicas de imaginologia por ressonância magnética (RM). A RM se apresenta hoje como a modalidade de imagem principal na avaliação da próstata. Esta técnica permite combinar dados anatômicos com os funcionais e através de uma abordagem multiparamétrica possibilita uma classificação mais assertiva do câncer da próstata (PEREZ; BRADY'S, 2013).

Atualmente, a RM é a única modalidade que pode ser usada para avaliar se o tumor é unilobar ou bilobar, sua extensão extracapsular e invasão da vesícula seminal, e/ou possível invasão de outras estruturas adjacentes, tais como bexiga, reto, esfíncter externo ou parede pélvica (ANDERSON-JACKSON; MCGROWDER; ALEXANDER-LINDO, 2012; CITAK-ER et al., 2014). 
Tradicionalmente, os sistemas de estadiamento clínico e patológico foram utilizados isoladamente, mas agora eles são utilizados principalmente como componentes de sistemas de risco-estratificação. O sistema de estadiamento TNM ( $T$ de Tumor, $N$ de Nódulo e $M$ de Metástase) é baseado em denominações distintas para o tumor primário, linfonodos regionais e metástases à distância. Todas as informações antes do primeiro tratamento definitivo podem ser utilizadas para o estadiamento clínico, incluindo estudos de imagem. O sistema de estadiamento TNM está apresentado na Tabela 1.

Tabela 1 - Classificação de tumores malignos TNM conforme American Joint Comittee on Cancer 2010

\begin{tabular}{|c|c|c|c|c|c|}
\hline Grupo & Estágio T & Estágio N & Estágio M & PSA & $\begin{array}{l}\text { Pontuação } \\
\text { de Gleason }\end{array}$ \\
\hline \multirow[t]{5}{*}{ I } & T1a-c & NO & MO & $<10$ & $\leq 6$ \\
\hline & T2a & NO & MO & $\geq 10,<20$ & $\leq 6$ \\
\hline & T2a & No & MO & $<20$ & 7 \\
\hline & $\mathrm{T} 1-2^{\mathrm{a}}$ & No & Mo & $X$ & $X$ \\
\hline & T1a-c & NO & MO & $<20$ & $\leq 6$ \\
\hline \multirow[t]{4}{*}{ IIA } & T1a-c & NO & MO & $\geq 10,<20$ & $\leq 7$ \\
\hline & T2a & NO & MO & $<20$ & $\leq 7$ \\
\hline & $\mathrm{T} 2 \mathrm{~b}$ & NO & MO & $<20$ & $x$ \\
\hline & $\mathrm{T} 2 \mathrm{~b}$ & NO & Mo & $X$ & Algum \\
\hline \multirow[t]{3}{*}{ IIB } & T2c & No & MO & Algum & Algum \\
\hline & T1-2 & NO & MO & $\geq 20$ & $\geq 8$ \\
\hline & T1-2 & No & MO & Algum & Algum \\
\hline III & T3a-b & No & MO & Algum & Algum \\
\hline \multirow[t]{3}{*}{ IV } & $\mathrm{T} 4$ & NO & MO & Algum & Algum \\
\hline & Algum T & N1 & MO & Algum & Algum \\
\hline & Algum T & Algum N & M1 & Algum & Algum \\
\hline
\end{tabular}

Fonte: American Joint Comittee on Cancer 2010

Os fatores prognósticos utilizados tem sido o estadiamento da doença através da pontuação de Gleason, classificação TNM e dosagem do PSA. Para simplificar a recomendação do tratamento e do prognóstico da doença para cada caso, dentre as diversas propostas de esquemas de classificação de riscos apresentadas o esquema proposto por D'Amico se tornou o mais utilizado e 
adotado pelo National Comprehensive Cancer Network (NCCN) guidelines (D'AMICO et al., 1998; MOON; PARK; LEE, 2010; REESE et al., 2012).

O câncer de próstata segundo a classificação de D'Amico, divide-se em baixo risco, risco intermediário e alto risco conforme os critérios apresentados na tabela a seguir (Tabela 2):

\subsection{Tratamento}

O tratamento padrão para cada estágio do câncer de próstata ainda permanece controverso. No processo de aconselhamento das opções terapêuticas, é importante apresentar todos os dados disponíveis sobre a história natural da doença, prognóstico, o potencial benefício terapêutico das várias modalidades, bem como as sequelas tardias relacionadas ao tratamento. $O$ tratamento deste câncer possui influencia considerável sobre a qualidade de vida, função sexual e expectativa de vida do paciente que devem ser discutidas amplamente com 0 paciente e sua companheira.

Tabela 2 - Sistema de classificação D’Amico para o câncer de próstata.

\begin{tabular}{ll|l|l|l|}
\multicolumn{1}{c|}{ Classificação } & \multicolumn{1}{c|}{ TNM } & \multicolumn{1}{c|}{ PSA } & \multicolumn{1}{c|}{ Gleason } \\
\hline Baixo Risco & T1c a T2a & $<10 \mathrm{ng} / \mathrm{mL}$ & $<=6$ \\
\hline Risco Intermediário & T2b ou T2c & 10 a $20 \mathrm{ng} / \mathrm{mL}$ & 7 \\
\hline Alto Risco & T3a & $>20 \mathrm{ng} / \mathrm{mL}$ & 8 a 10 \\
\hline $\begin{array}{l}\text { Doença localmente avançada } \\
\text { Fonte: D'AMICO }\end{array}$ & T3b ou T4 & & \\
\hline
\end{tabular}

As opções terapêuticas atuais para o tratamento do câncer de próstata são: cirúrgica, através da prostatectomia radical (GAINSBURG et al., 2010) e técnicas terapêuticas com altas doses de radiação dividida em: radioterapia externa conformacional, radioterapia de intensidade modulada, radioterapia interna ou braquiterapia que serão melhor descritas a seguir (BOORJIAN et al., 2011; HU et al., 2015; MILECKI et al., 2014; ROACH, 2014). Na ausência de estudos criteriosos que demonstrem a superioridade de um tratamento sobre o outro, existem grandes variações na escolha preferencial para a intervenção terapêutica em estágios iniciais do câncer de próstata praticada em todo o mundo. 
Para os pacientes de baixo risco não existem diferenças significativas para o acompanhamento bioquímico e sobrevida livre da doença quando tratados com a opção cirúrgica ou de radioterapia (BOORJIAN et al., 2011; ZELEFSKY et al., 2011).

Para os pacientes de risco intermediário e alto a opção terapêutica amplamente utilizada é combinação da radioterapia externa com a terapia hormonal supressora de andrógenos (HOFFMAN et al., 2013; ZHOU et al., 2009).

Quando o tumor está confinado à próstata a indicação de prostatectomia radical (PR) como opção terapêutica vem acontecendo desde a década de 70 . No passado, segundo a maioria dos urologistas, a PR teve um papel limitado no tratamento da doença extracapsular grave ou com envolvimento das vesículas seminais ou na presença de metástases linfáticas; no entanto, mais recentemente, tem havido um aumento do uso de cirurgia para a doença localmente avançada também. Duas abordagens para a PR clássica são utilizadas: retropúbica e perineal (PEREZ; BRADY'S, 2013).

\subsubsection{Radioterapia para tratamento do câncer de próstata}

A radioterapia é uma modalidade de tratamento com radiação ionizante com a finalidade de destruir células tumorais, com o intuito de erradicar o tumor ou ao menos diminuir o seu tamanho, propiciar uma melhora na qualidade de vida do paciente ou tratar complicações da doença como sangramento e dor (PEREZ; BRADY'S, 2013).

A radioterapia para o tratamento de câncer vem apresentando novas tendências. Doses de radiação mais elevadas e o uso de terapia de privação de andrógeno (TPA) adjuvante com radioterapia para vários grupos de riscos estão mais comuns do que no passado (PEREZ; BRADY'S, 2013).

Tradicionalmente, as opções de tratamento para pacientes em estágio inicial com câncer de próstata clinicamente localizado (estágios T1c ou T2) incluem: $\mathrm{PR}$, radioterapia ou a implantação intersticial permanente. As técnicas cirúrgicas têm melhorado significativamente, em 1997, Walsh e col. popularizaram a técnica que preserva os nervos reduzindo a incidência de impotência sexual em cerca de $30 \%$ a $60 \%$, dependendo da idade do paciente, da fase do tumor e da extensão da cirurgia, enquanto PR clássica resultava em quase 100\% de incidência. Além disso, 
o acesso aos métodos melhorados também possibilitou reduzir os riscos póstratamento de incontinência urinária.

Dentre as técnicas de radioterapia utilizadas para tratamento de câncer de próstata existem: a 2D (ou convencional - CRT) e a 3D-Conformacional. Entre as técnicas 3D mais disseminadas e em desenvolvimento têm-se as: IMRT (Intensity Modulated Radiation Therapy - Modulação da Intensidade do Feixe), IGRT (Image-guided radiotherapy - Radioterapia Guiada por Imagem), Radioterapia Esteriotáxica (Radiocirurgia), Protonterapia, BNCT (Boron Neutron Capture Therapy) dentre outras.

A Radioterapia guiada por imagem (IGRT) tem sido amplamente utilizada por usar informações geométricas e anatômicas em tempo real do paciente em tratamento podendo assim obter uma maior dose no tecido alvo e menos radiação nos tecidos adjacentes.

Radioterapia de intensidade modulada (IMRT) é uma modalidade de radioterapia altamente precisa que permite a administração de altas doses de radiação no volume alvo, minimizando as doses nos tecidos normais adjacentes de forma muito eficaz. A IMRT é uma evolução da 3D-RCT por ser capaz de modular o feixe de tratamento, oferecendo maior intensidade de dose na área de interesse poupando áreas onde está intensidade não é desejada (Danthai, T. et al., 2009).

Atualmente as pesquisas a cerca destas técnicas visam aprimorá-las com o intuito de melhorar a qualidade do tratamento levando em consideração o resultado obtido e a redução dos efeitos colaterais (HUMMEL et al., 2010; WILT et al., 2008; ZELEFSKY et al., 2011; ZHOU et al., 2009).

Resultados melhorados e diminuição de toxicidade estão sendo obtidos através da implantação intersticial permanente usando técnicas transperineal guiada por ultrassom e o uso de braquiterapia possibilitando uma melhor distribuição das doses para esta abordagem de tratamento (PEREZ; BRADY'S, 2013; WALSH et al., 2014; ROSTELATO, Maria E.C.M.,2005)

Nos casos de câncer de próstata localmente avançado as opções de tratamento são diversas, e não existem critérios definidos que auxiliem na escolha pela melhor opção levando-se em consideração a eliminação do tumor e a minimização dos efeitos colaterais. Diversos estudos analisando testes clínicos e pesquisas observacionais permitiram concluir que não existe alteração na taxa de mortalidade ao variar o regime de irradiação de feixe externo. Apesar da definição 
de eventos adversos e gravidade variarem muito entre os estudos é possível concluir que incontinência urinaria é mais comum após o tratamento com PR do que com terapia de radiação enquanto a urgência urinária foi mais frequente com radiação. Já a disfunção erétil ocorre frequentemente após todo tratamento (WILT et al., 2008). Os estudos apresentam uma associação da IMRT com uma menor taxa de complicação intestinal, proctite e hemorragias quando comparada com 3DConvencional (BEKELMAN et al., 2011). Já, Sheets e col. (2012), apresentaram uma maior incidência de disfunção erétil nos pacientes tratados com IMRT versus 3D-Concencional. Segundo um estudo com 64 pacientes em estágios intermediários e avançados tratados com IMRT combinado com terapia endócrina desenvolveram efeitos colaterais agudos de proctite e cistite. O único fator prognóstico que influenciou a gravidade da proctite foi o volume do tumor antes do tratamento $(p<0,05)$ (LUO et al., 2013).

Mesmo quando a cura da doença não é objetivo fim da radioterapia, a sua utilização é indicada para melhorar a qualidade de vida, uma vez que as aplicações diminuem o tamanho do tumor, e com isso pode levar ao alívio da pressão, reduzir hemorragias, dores, metástases e outros sintomas.

\subsubsection{Efeitos Colaterais}

O tratamento com radioterapia no câncer de próstata frequentemente está associado com uma vasta possibilidade de efeitos colaterais significativos. Esses efeitos colaterais são comumente classificados em agudos ou tardios de acordo com o momento em que se manifestam em relação ao tratamento.

Os efeitos agudos são aqueles que ocorrem tipicamente dentro de alguns dias ou semanas do início do tratamento até 90 dias e acometem preferencialmente os tecidos que apresentam maior capacidade proliferativa, podem ser tratados sintomaticamente e geralmente são bem tolerados e reversíveis. Os mais comuns, entretanto, menos importantes, no quesito gravidade são aqueles relacionados com a pele, como ressecamento, coceira, bolhas ou descamação e aqueles relacionados com a fadiga, uma falta de energia que não melhora com o repouso (PEREZ; BRADY'S, 2013).

Os efeitos tardios ocorrem após 90 dias do início do tratamento e podem chegar a se manifestar 5 anos deste início. São mais raros e ocorrem geralmente 
quando a dose de radiação nos tecidos normais é ultrapassada e se manifestam por atrofias e fibrose, já as alterações de caráter genético e formação de novos tumores são bem raras (PEREZ; BRADY'S, 2013).

Não é possível proporcionar uma orientação abrangente sobre a gestão de todas as possíveis complicações do tratamento a não ser para os mais importantes por serem mais comuns e afetarem seriamente a qualidade de vida dos pacientes, sendo eles: problemas retais, de disfunção sexual e incontinência urinária (PEREZ; BRADY'S, 2013).

O estudo quantitativo e qualitativo da toxicidade do tratamento do câncer, de forma padronizada, auxilia na comparação entre os diversos tratamentos disponíveis, permitindo ainda a uniformização da linguagem utilizada. Entre os critérios mais utilizados por pesquisadores clínicos para avaliação da toxicidade do tratamento antineoplásico estão os Critérios Comuns de Toxicidade (CTC), desenvolvidos pelo National Cancer Institute $(\mathrm{NCl})$ norte-americano, versão 4.03, em outubro a versão 5.0 que está em fase de rascunho, coletando contribuições dos pesquisadores deve ser disponibilizada pelo site do NIC/NIH ( National Cancer Institute, 2015).

Com o intuito de uniformizar a graduação dos eventos adversos avaliados nesse trabalho será utilizada a tabela dos CTC, disponibilizada pelo National Cancer Institue.

Apesar do uso histórico do termo toxicidade, recomenda-se que o mesmo não seja mais utilizado e substituído pelo termo Evento Adverso (EA). Eventos Adversos são definidos como qualquer sintoma desfavorável, sinal ou doença (incluindo um achado laboratorial anormal), associados com a utilização de um tratamento ou procedimento médicos que, podem ou não, estar relacionados (PEREZ; BRADY'S, 2013).

Critérios de Toxicidade Comum (CTC) fornecem uma terminologia descritiva para o relatório de EA. A gravidade ou escala de classificação é fornecida para cada EA conforme discriminado a seguir (PEREZ; BRADY'S, 2013):

Grau 1: leve; assintomático ou sintomas leves, ou apenas diagnóstico clínico e observação, sem indicação de intervenção.

Grau 2: moderado; intervenção mínima, local ou não invasiva; limitação das atividades diárias. 
Grau 3: grave; clinicamente significativo, mas não apresenta risco de vida, nem necessidade de hospitalização ou o prolongamento da hospitalização, incapacitante; limitação do autocuidado.

Grau 4: risco de vida; intervenção urgente indicada.

Grau 5: Morte relacionada ao EA.

Eventos adversos graves associados com a terapia de radiação estão discriminados no ANEXO 3 que contém a tradução do CTCAE v4.0.

\section{Eventos adversos agudos}

A maioria destes eventos adversos agudos é idêntica aos que foram induzidos por outras modalidades, embora alguns tenham critérios especiais adicionados para ajudar na classificação quando se acredita que o EA está associado com a radioterapia.

Os EA relacionados com a radiação incluídos no CTCAE são:

- Dermatite de radiação

- Reação de recordação da radiação

- Disfagia esofágica relacionada à radiação

- Disfagia faríngea relacionada à radiação

- Mucosite devido à radiação

- Dor devido à radiação

Foi desenvolvido um EA separado para dor devido à radiação.

\section{Eventos adversos tardios}

Os EA tardios são classificados de acordo com um sistema de pontuação separado. Estes critérios são um esquema de pontuação de morbidade RTOG / EORTC que incluem:

- bexiga; osso; cérebro; esôfago; coração; rim; articulação; laringe; fígado; pulmão; membrana mucosa; glândulas salivares; pele; intestino delgado e grosso; medula óssea; tecido subcutâneo; olhos; outros. 


\section{METODOLOGIA}

Foi realizado um estudo prospectivo, observacional, longitudinal, tipo Coorte. Todos os pacientes elegíveis para o tratamento radical com radioterapia admitidos no período de um ano, entre setembro de 2016 e setembro de 2017, foram incluídos na pesquisa. A amostra foi definida como amostragem não probabilística utilizando-se da amostra de conveniência. Todos os pacientes dentro critério de inclusão foram convidados a participar desse estudo no período estipulado. Aceitaram participar 45 pacientes diagnosticados com câncer de próstata. O trabalho foi realizado no Serviço de Radioterapia da Unidade de Oncologia do Hospital Márcio Cunha. Esse trabalho foi aprovado pelo Comitê de Ética em Pesquisa da UNILESTE, sob o número CAAE 56573816.2.0000.5095 ANEXO 4.

A partir de setembro de 2016, aqueles pacientes que aceitaram participar e preencheram os critérios predefinidos descritos a seguir foram incluídos no estudo. O recrutamento aconteceu ao longo de 12 meses. Durante a primeira consulta com a equipe de médicos radio-oncologistas ou médicos em residência em radioterapia, o paciente foi convidado a participar e a ele foi garantido que sua entrada ou não no estudo não prejudicaria em nada seu tratamento. Além disso, foi esclarecido que a sua entrada no estudo também não alteraria o seu protocolo terapêutico uma vez que este é um estudo observacional. A consulta aconteceu na Unidade de Oncologia em consultório reservado.

O tratamento radioterápico foi dividido em três fases para melhor entendimento. Por ordem cronológica são elas: consulta clínica (fase 1), Tomografia Computorizada (TC) de planeamento, simulação e tratamentos de radioterapia (fase 2). Durante a fase dois os relatos de eventos adversos foram registrados no instrumento de coleta de dados ANEXO 2, conforme o paciente procurou o serviço em função da sua manifestação ou durante as 3 consultas de revisão pré-agendadas durante o tratamento. Após três meses de tratamento iniciou-se a fase três, quando o paciente foi avaliado clinicamente e comunicado do término do estudo, apesar da sua permanência no programa de tratamento e/ou acompanhamento na Unidade de Oncologia. Os pormenores de cada fase foram melhores descritos a seguir. 
$\mathrm{Na}$ primeira fase, o paciente candidato a entrar no estudo foi avaliado durante sua primeira consulta quanto aos seguintes critérios:

\section{Critérios de inclusão:}

Pacientes acima de 18 anos diagnosticados com câncer de próstata e encaminhados ao serviço de radioterapia da Unidade de Oncologia do Leste de Minas para tratamento com radioterapia conformacional (IMRT).

\section{Critérios de exclusão:}

Pacientes incapazes, com indicação de prostatectomia; pacientes graves cujo tratamento de radioterapia seja contraindicado; paciente com histórico de tratamento loco-regional anterior ao câncer de próstata; evidência clínica ou de imagem de doença disseminada; ressecção transuretral recente; com limitações neurológicas.

Uma vez que o paciente atendeu aos critérios para entrar no estudo, durante sua consulta com o médico radio-oncologista ou o residente em radioterapia, o mesmo foi convidado a participar do estudo através da apresentação do Termo de Consentimento Livre e Esclarecido (TCLE) ANEXO 1 conforme Resolução 466, do MS. Os devidos esclarecimentos que se fizerem necessários foram realizados e o paciente que concordou em participar do estudo assinou o TCLE. O paciente foi então avaliado clinicamente seguindo os critérios apresentados no ICD.

A fase dois foi relativa ao protocolo de tratamento do paciente que incluiu o planejamento para a radioterapia e registro dos eventos adversos (EA). Antes de iniciar a primeira sessão, cada paciente foi submetido a uma série de etapas descritas a seguir (GIGLIOLI, 2012):

I. Simulação do tratamento: tem o objetivo de determinar a melhor posição do paciente, de forma a garantir uma melhor reprodutibilidade diária e otimizar a irradiação do volume alvo ao mesmo tempo que minimiza a exposição dos tecidos sadios;

II. Tomografia: é realizada conforme a posição determinada na simulação do tratamento;

III. Delineamento: os médicos realizam um desenho delimitando a área a ser tratada e quais órgãos devem ser protegidos por uma limitação de dose; 
IV. Planejamento: os físicos determinam a melhor maneira de irradiar de forma a distribuir de forma homogênea a dose no tecido alvo minimizando a dose nos tecidos sadios adjacentes;

V. Aprovação: o plano de tratamento é avaliado em conjunto pelo médico e pelo físico para enfim liberar o paciente para que ele inicie as sessões de radioterapia;

VI. Conferência do cálculo: outro físico deve recalcular o tempo de exposição e a unidade monitora através de outro sistema de cálculo independente do primeiro para conferir se estão corretos;

VII. Dose da Radiação: É utilizado a dose de 72 gray divididos em 36 porções.

Já na primeira consulta o médico fez a indicação para a realização da TC de planejamento. É consensual que a realização da TC é imprescindível para a aquisição de imagens anatômicas das zonas a irradiar, para determinação da área tumoral. É na TC de planejamento que é definido o posicionamento de cada paciente. Posteriormente, as imagens de TC são enviadas para o sistema de planejamento computadorizado com o intuito de obter uma distribuição da dose prescrita nas zonas a irradiar. $\mathrm{O}$ acelerador linear (figura 2), contém um sistema mecânico, um sistema de localização, uma mesa de posicionamento e permite avaliar o correto posicionamento dos campos de set-up e/ou campos de tratamento (PEREZ; BRADY'S, 2013). Na preparação do paciente, recomenda-se, a bexiga confortavelmente cheia para a realização do TC de planejamento e ao longo dos tratamentos.

Figura 2 - Acelerador Linear

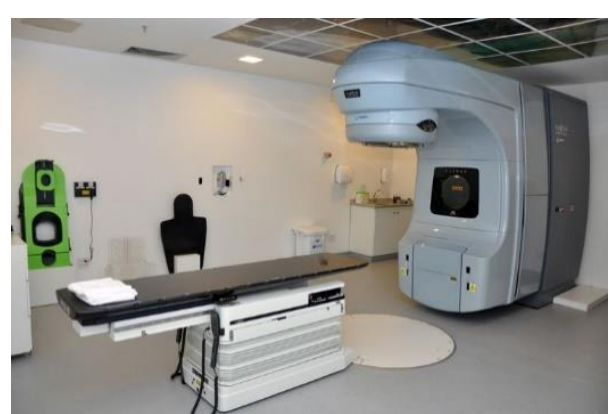

Fonte: https://www.campos.ri.gov.br/exibirNoticia.php?id noticia=32111 
Para descrever um tratamento com radiações ionizantes, foram necessários, no mínimo, três parâmetros: volume tratado, dose de radiação e técnica utilizada. Esses parâmetros são aplicados de maneira uniforme, e de acordo com os protocolos que cada instituição adota. Os volumes de tratamento foram definidos de acordo com a Comissão Internacional de Unidades e Medidas de Radiação (ICRU) (ALMOND et al., 1999). A massa palpável de tumor foi definida como volume de tumor visível, GTV (do inglês Gross tumor volume). O volume que contem além do GTV a doença microscópica maligna foi denominado volume clínico do alvo, CTV (do inglês clinical target volume). Já o volume que leva em consideração os efeitos de todas as variações geométricas como: movimentos de órgãos ou incerteza da sua posição, com o intuito de assegurar que a dose devida foi entregue ao CTV denomina-se volume do planejamento do alvo, PTV (do inglês planning target volume). Para melhor controlar a irradiação nos volumes sadios realiza-se também o delineamento dos órgãos de risco com o intuito de conhecer e controlar a dose irradiada nos mesmos impedindo que ultrapasse a dose de tolerância destes tecidos. Este último volume denomina-se planejamento do órgão de risco (PORV do inglês planning organs risk volume) considerando não só o contorno físico como as possibilidades de movimentação dentro do paciente. E para finalizar define-se também como volume tratado (TV do inglês treatment volume) o volume que efetivamente recebeu a dose prescrita e volume irradiado (IV, do inglês irradiated volume) como uma dose que seja importante ser reportada para o tipo de paciente em questão (POLI, M. E. R., 2007).

$\mathrm{Na}$ figura 3, retirada da tese de Doutorado de Poli (2007), pode ser visualizado o esquema dos volumes apresentados

Figura 3 - Definição dos volumes alvos e órgãos de risco

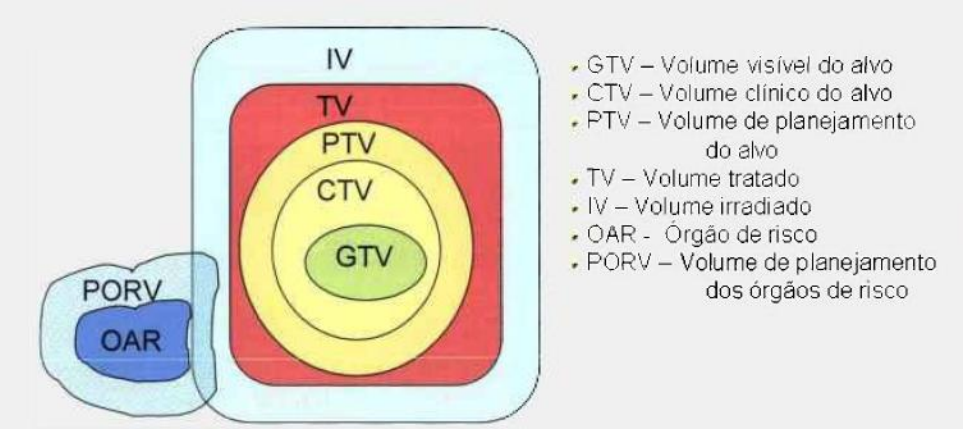

Fonte: POLI, M. E. R. Definição do volume de planejamento do alvo (ptv) e seu efeito na radioterapia. 
Neste trabalho para o planejamento do tratamento do câncer de próstata, os pacientes foram submetidos inicialmente a uma simulação em aparelho Acuity (Varian Medical Systems; Palo Alto, CA, EUA). Permaneceram em decúbito dorsal, com os tornozelos fixados e as mãos sobre o peito. Foi localizado o isocentro, definido por meio da TC com campo $10 \times 10 \mathrm{~cm}$ com centro na linha média do paciente e limite inferior na borda inferior do púbis, e radiografia lateral com limite anterior do campo de 1 a $1,5 \mathrm{~cm}$ posterior à borda do púbis. Tais pontos foram marcados externamente na pele dos pacientes. Estas mesmas condições de posicionamento foram aplicadas no acelerador linear Clinac $^{\circledR}$ IX, (Varian Medical Systems; Palo Alto, CA, EUA). As imagens da tomografia foram processadas no sistema de planejamento computadorizado Eclipse (Varian Medical Systems; Palo Alto, CA, EUA). Posteriormente, foram definidos o CTV e o PTV, CTV com adição de margem de $10 \mathrm{~mm}$, exceto na porção posterior, que foi de $7 \mathrm{~mm}$.

Em relação ao tratamento, os pacientes receberam dose de 72 Gray distribuídas em 36 porções. Nos pacientes foram utilizadas de quatro a seis campos de tratamento. O limite delimitado para o deslocamento do posicionamento foi de $2,5 \mathrm{~mm}$, estabelecido como erro padrão $(E P=2,5 \mathrm{~mm}$ ). Para variações maiores de 2,5 mm estabeleceu-se a correção no acelerador linear.

A avaliação dos EA agudos nos pacientes tratados com radioterapia conformacional foi realizada de forma prospectiva através das coletas dos dados clínicos do paciente por um médico radio-oncologista presente na equipe durante a rotina de avaliação de seguimento. Todos os envolvidos para coleta dos dados neste projeto passaram por um treinamento prévio de forma a garantir a qualidade dos dados coletados e a conduta ética. Os dados de toxicidade foram avaliados e registrados no ICD onde os pacientes foram questionados pela presença ou ausência dos sintomas. A primeira consulta ocorreu após 30 dias do início do tratamento de radioterapia e as demais consultas com intervalo de 30 dias entre elas, totalizando um período de 3 meses de acompanhamento desses pacientes. Os tratamentos dos EA foram realizados conforme os protocolos clínicos padronizados na instituição.

\section{Desfechos}

Foram considerados como desfechos os seguintes EA agudos: polaciúria (frequência urinária idiopática benigna), resíduo urinário (a bexiga não se esvazia completamente e permanece urina residual na bexiga), disúria (um sintoma 
de dor, desconforto ou queimação ao urinar), incontinência urinária (vazamento involuntário de urina), hematúria (presença de glóbulos vermelhos na urina), diarreia (fezes soltas ou aquosas), fadiga / astenia (estado de cansaço ou exaustão resultante de esforço físico ou mental), dor na defecação, dor tipo cólica e náusea ou vômito. Todos os envolvidos na coleta de dados neste projeto foram submetidos a treinamento prévio, a fim de garantir a qualidade dos dados coletados e a conduta ética.

\section{Análise Estatística}

Os dados foram submetidos às análises descritivas e de frequências. As variáveis qualitativas foram expressas na forma de números e porcentagens e os parâmetros clínicos e técnicos foram categorizados. Como medida de tendência central utilizou-se o cálculo da média aritmética e para a medida de dispersão dos dados o desvio padrão. Para o cálculo da incidência do EA por consulta, utilizou-se como numerador o número de consultas por paciente tendo esse paciente manifestado um ou mais EA e como denominador o número de eventos ocorridos considerando o número de pacientes (45) vezes o número de consultas para cada paciente (3), totalizando 135 eventos. Para a avaliação da associação entre a idade, etnia e grau de escolaridade com a presença ou não do desfecho de toxicidade, calculou-se o odds ratio (OR - é utilizado como medida de associação em estudos caso-controle e em estudos transversais controlados). O Erro Padrão e o intervalo de confiança de 95\% foi calculado conforme Altman (1991). Em todas as análises estatísticas foi adotado um nível de significância de $5 \%(p<=0,05)$. Utilizou-se os programas Excel e Sofware Prisma 6 (versão 6.01) para os cálculos. 


\section{RESULTADOS E DISCUSSÃO}

A média de idade dos pacientes incluídos nesse estudo foi de $70 \pm 15,1$ anos, com predominância de etnia branca, grau de escolaridade do ensino fundamental e estado civil casado. Sobre a ocupação, destaca-se um equilíbrio entre aposentados e trabalhadores (Tabela 3).

TABELA 3 - Dados demográficos dos pacientes $(n=45)$

\begin{tabular}{|c|c|c|}
\hline Idade (anos) & $\mathbf{N}$ & $\%$ \\
\hline$\leq 70$ & 23 & $51,1 \%$ \\
\hline$>70$ & 22 & $48,9 \%$ \\
\hline Idade média (anos(DP);MIN-MAX) & $70,2( \pm 15,1)$ & $(54,6-86,8)$ \\
\hline \multicolumn{3}{|l|}{ Etnia } \\
\hline Branco & 20 & $44 \%$ \\
\hline Amarelo & 3 & $7 \%$ \\
\hline Pardo & 17 & $38 \%$ \\
\hline Negro & 5 & $11 \%$ \\
\hline Indígena & 0 & $0 \%$ \\
\hline \multicolumn{3}{|l|}{ Grau de escolaridade } \\
\hline Não informou & 3 & $6,7 \%$ \\
\hline Ens. Fund. Inc. & 18 & $40,0 \%$ \\
\hline Ens. Fund. Comp. & 15 & $33,3 \%$ \\
\hline Ens. Méd. Inc. & 2 & $4,4 \%$ \\
\hline Ens. Méd. Comp. & 7 & $15,6 \%$ \\
\hline Ens. Sup. Inc. & 0 & $0,0 \%$ \\
\hline Ens. Sup. Comp. & 0 & $0,0 \%$ \\
\hline Pós Grad. & 0 & $0,0 \%$ \\
\hline \multicolumn{3}{|l|}{ Ocupação } \\
\hline Aposentado & 24 & $53,3 \%$ \\
\hline Trabalhando & 21 & $46,7 \%$ \\
\hline \multicolumn{3}{|l|}{ Estado Civil } \\
\hline Solteiro & 3 & $6,7 \%$ \\
\hline Casado & 34 & $75,6 \%$ \\
\hline União estável & 5 & $11,1 \%$ \\
\hline Separado & 1 & $2,2 \%$ \\
\hline Viúvo & 2 & $4,4 \%$ \\
\hline
\end{tabular}

Fonte: autor da dissertação 
$\mathrm{Na}$ tabela 4, a avaliação da classificação de risco apresentou uma distribuição homogênea entre os riscos baixo, intermediário e alto. A maioria dos pacientes $(57,8 \%)$ apresentou classificação tumoral em estágio inicial de baixo risco (T1), seguida de risco intermediário $(33,3 \%)$ e alto risco $(8,9 \%)$. Com base no escore de Gleasson, 44,0\% apresentou valor abaixo de 6 (baixo), 40,0\% intermediário e 15,5\% alto. Analisando o nível de PSA, 62,2\% apresentaram menos de $10 \mathrm{ng} \cdot \mathrm{ml}^{-1}, 22,2 \%$ de nível intermediário $\left(10-20 \mathrm{ng} \mathrm{ml}^{-1}\right)$ e 15,6\% acima de 20 $\mathrm{ng} \cdot \mathrm{ml}^{-1}$.

TABELA 4 - Classificação de risco dos pacientes $(n=45)$

\begin{tabular}{|l|l|l|}
\hline Classificação de Risco & N & $\%$ \\
\hline Baixo & 15 & $33,3 \%$ \\
\hline Intermediário & 14 & $31,1 \%$ \\
\hline Alto & 16 & $35,6 \%$ \\
\hline Estágio Inicial do Tumor (TNM) & & \\
\hline Baixo Risco (T1) & 26 & $57,8 \%$ \\
\hline Risco Intermediário (T2) & 15 & $33,3 \%$ \\
\hline Alto Risco (T3) & 4 & $8,9 \%$ \\
\hline Pontuação de Gleason & & \\
\hline Baixo (< 6) & 20 & $44,4 \%$ \\
\hline Intermediário (7) & 18 & $40,0 \%$ \\
\hline Alto (8 - 10) & 7 & $15,5 \%$ \\
\hline PSA (ng/mL) & & \\
\hline$<10$ & 28 & $62,2 \%$ \\
\hline $10-20$ & 10 & $22,2 \%$ \\
\hline$>20$ & 7 & $15,6 \%$ \\
\hline
\end{tabular}

Fonte: autor da dissertação

Não foi possível identificar associação significativa entre as variáveis: idade, etnia e escolaridade em relação às manifestações de efeitos adversos (Tabela 5). No entanto, existe uma tendência para indivíduos pardos ou negros terem maior chance de incidência de toxicidade aguda do que pacientes brancos. Pesquisas recentes têm apoiado a presença de fatores de risco genéticos para 
reparo de feridas e toxicidade da radiação. Parece que os genes de reparo de feridas podem variar significativamente entre os diferentes grupos étnicos. aumento da frequência de uma longa repetição de bases do DNA (ácido desoxiribonucleico) GT (guanina e timina) no promotor HMOX1 foi associado a efeitos tardios em populações afro-americanas e caucasianas. Os polimorfismos de nucleotídeo único (SNP) rs1800469 no promotor TGFß1 e o SNP rs6721961 no promotor NFE2L2 também se associaram significativamente aos efeitos tardios em afro-americanos, mas não em caucasianos [29]. Além disso, há uma pesquisa que combina análise pareada e explora disparidades na qualidade de vida relacionada à saúde e toxicidades comuns entre 1.536 pacientes afro-americanos e brancos com câncer de próstata clinicamente localizado, tratados com terapia de prótons.

Após 2 anos de acompanhamento, não houve disparidades na qualidade de vida relacionada à saúde, Critérios de Terminologia Comuns relatados pelo médico para toxicidade gastrointestinal (Gl) ou recaída bioquímica. Não foi detectada diferença nas pontuações calculadas pelo Índice de Próstata Expandida resumido, com de 26 questões sobre: incontinência urinária, obstrução urinária ou toxicidade intestinal, entre os dois grupos, nem houve diferença na toxicidade gastrointestinal grau 2 ou superior $(P=0,45)$. Os afro-americanos não tiveram uma incidência de toxicidade geniturinária tardia grau 3 estatisticamente significativa em relação aos caucasianos $(4,4 \%$ vs. $0 \% ; P=0,12)$ [30]. Vale ressaltar que uma pesquisa comparando dados de toxicidade coletados prospectivamente em 394 pacientes com câncer de próstata que receberam tratamento com técnicas contemporâneas de terapia por IMRT e feixe de prótons e esquemas de fracionamento de dose semelhantes, os riscos de toxicidades agudas e tardias de GI / GU (geniturinárias) não diferiram significativamente após o ajuste para fatores de confusão e preditores [31]. De fato, estudos futuros devem explicar a possibilidade de toxicidade da radiação ter discrepância entre as etnias. 
TABELA 5 - Relação entre as características demográficas e a manifestação de toxicidade aguda

\begin{tabular}{|c|c|c|c|c|}
\hline & $\begin{array}{r}\text { TOXIC } \\
\text { AG }\end{array}$ & $\begin{array}{l}\text { IDADE } \\
\text { JDA }\end{array}$ & ODDS RATIO & VALOR DE P \\
\hline & $\begin{array}{c}\text { AUSEN } \\
\text { TE }\end{array}$ & $\begin{array}{l}\text { PRESE } \\
\text { NTE }\end{array}$ & $(95 \% \mathrm{Cl})$ & \\
\hline $\begin{array}{l}\text { Características } \\
\text { Demográficas }\end{array}$ & $\mathrm{N}$ & $\mathrm{N}$ & & \\
\hline Idade (anos) & & & $>70 / \leq 70$ & \\
\hline$\leq 70$ & 5 & 28 & 0,8 & 0,77 \\
\hline$>70$ & 4 & 18 & $(0,2$ a 3,4$)$ & \\
\hline Etnia & & & PN/Branco & \\
\hline Branco & 6 & 14 & 4,3 & 0,10 \\
\hline Pardo e Negro & 2 & 20 & $(0,8$ a 24,4$)$ & \\
\hline Grau de escolaridade & & & EF/EM & \\
\hline Ens. Fund. Inc./Comp. & 9 & 24 & 7,4 & 0,18 \\
\hline Ens. Méd. Inc./Comp. & 0 & 9 & $(0,4$ a 139,5$)$ & \\
\hline
\end{tabular}

Fonte: autor da dissertação

A maioria dos pacientes $(80,0 \%)$ apresentou alguma toxicidade neste estudo, mas a toxicidade também não apresentou uma associação significativa conforme as características clínicas avaliadas: como classificação de risco, estágio inicial do tumor, escore de Gleason e nível de PSA (Tabela 5). Por outro lado, um estudo piloto de IMRT altamente hipofracionado por 3 semanas para câncer de próstata localizado com uma dose nominal de 54 Gray em 15 frações (3,6 Gray por fração) apresentou 24,0\% de toxicidade aguda. De outro modo, este estudo ainda tem duas importantes limitações: foi um estudo piloto com 25 pacientes e o período médio de acompanhamento foi de 31 meses, o que é muito curto para tirar conclusões sobre toxicidades tardias e resultados de controle de tumores [19]. 
TABELA 6 - Relação entre as características clínicas e a manifestação de toxicidade aguda ( $n=45)$

\begin{tabular}{|c|c|c|c|c|}
\hline \multirow{2}{*}{ Características Clínicas } & \multicolumn{2}{|c|}{$\begin{array}{c}\text { SEM } \\
\text { TOXICIDADE }\end{array}$} & \multicolumn{2}{|c|}{$\begin{array}{c}\text { COM } \\
\text { TOXICIDADE }\end{array}$} \\
\hline & $\mathrm{N}$ & $\%$ & $\mathrm{~N}$ & $\%$ \\
\hline Baixo & 2 & $22,2 \%$ & 13 & $36,1 \%$ \\
\hline Intermediário & 4 & $44,4 \%$ & 10 & $27,8 \%$ \\
\hline Alto & 3 & $33,4 \%$ & 13 & $36,1 \%$ \\
\hline \multicolumn{5}{|l|}{$\begin{array}{l}\text { Estágio Inicial do Tumor } \\
\text { (TNM) }\end{array}$} \\
\hline Baixo Risco (T1) & 4 & $44 \%$ & 22 & $61 \%$ \\
\hline Risco Intermediário (T2) & 5 & $56 \%$ & 10 & $28 \%$ \\
\hline Alto Risco (T3) & 0 & $0 \%$ & 4 & $11 \%$ \\
\hline \multicolumn{5}{|l|}{ Pontuação de Gleason } \\
\hline Baixo $(<6)$ & 6 & $67 \%$ & 14 & $39 \%$ \\
\hline Intermediário (7) & 2 & $22 \%$ & 16 & $44 \%$ \\
\hline Alto $(8-10)$ & 1 & $11 \%$ & 6 & $17 \%$ \\
\hline \multicolumn{5}{|l|}{ PSA (ng/mL) } \\
\hline$<10$ & 5 & $56 \%$ & 23 & $64 \%$ \\
\hline $10-20$ & 3 & $33 \%$ & 7 & $19 \%$ \\
\hline$>20$ & 1 & $11 \%$ & 6 & $17 \%$ \\
\hline
\end{tabular}

Fonte: autor da dissertação

A maior proporção de efeitos agudos $(59,1 \%)$ se manifestou durante a primeira consulta médica, prevalecendo o sintoma de polaciúria (64,1\%). Em relação aos sintomas de efeitos agudos mais prevalentes nas três consultas, destaca-se a polaciúria com 44,0\%, seguida de resíduo urinário (20,0\%), disúria $(9,0 \%)$, incontinência urinária $(8,0 \%)$ e hematúria $(8,0 \%)$. Não houve relato de dor cólica, náusea ou vômito. Sintomas como dor à defecação, fadiga e diarreia foram pouco relatados $(12,0 \%)$ (Tabela 7$)$. 
TABELA 7 - Manifestação de toxicidade aguda ao longo da consulta $(n=45)$

\begin{tabular}{|c|c|c|c|c|c|}
\hline \multirow[t]{2}{*}{ EFEITOS AGUDOS } & \multicolumn{3}{|c|}{ CONSULTA } & \multirow{2}{*}{$\begin{array}{l}\text { TOTAL } \\
\text { (N) }\end{array}$} & \multirow{2}{*}{$\begin{array}{c}\text { FREQ. } \\
(\%)\end{array}$} \\
\hline & $1^{a}$ & $2^{\mathrm{a}}$ & $3^{\mathbf{a}}$ & & \\
\hline POLACIÚRIA & 25 & 1 & 3 & 29 & $44 \%$ \\
\hline RESÍDUO URINÁRIO & 4 & 6 & 3 & 13 & $20 \%$ \\
\hline DISÚRIA & 2 & 3 & 1 & 6 & $9 \%$ \\
\hline INCONTINÊNCIA URINÁRIA & 3 & 1 & 1 & 5 & $8 \%$ \\
\hline HEMATURIA & 2 & 0 & 3 & 5 & $8 \%$ \\
\hline DIARRÉ|A & 0 & 3 & 1 & 4 & $6 \%$ \\
\hline FADIGA/ASTENIA & 2 & 0 & 0 & 2 & $3 \%$ \\
\hline DOR À DEFECAÇÃO & 1 & 1 & 0 & 2 & $3 \%$ \\
\hline DOR TIPO CÓLICA & 0 & 0 & 0 & 0 & $0 \%$ \\
\hline NÁUSEA OU VÔMITO & 0 & 0 & 0 & 0 & $0 \%$ \\
\hline Total & 39 & 15 & 12 & 66 & $100 \%$ \\
\hline
\end{tabular}

Fonte: autor da dissertação

A maioria dos pacientes $(64,4 \%)$ apresentou um ou dois eventos adversos, 20,0\% dos pacientes não apresentaram toxicidade para a radioterapia e apenas 15,5\% tiveram 3 ou 4 eventos adversos (Tabela 8).

TABELA 8 - Frequência de eventos adversos agudos ao longo do estudo $(n=45)$

\begin{tabular}{|c|c|c|}
\hline $\begin{array}{c}\text { EVENTOS } \\
\text { ADVERSOS }\end{array}$ & $\begin{array}{c}\text { NÚMERO DE } \\
\text { PACIENTES }\end{array}$ & $\begin{array}{c}\text { FREQUENCIA } \\
(\%)\end{array}$ \\
\hline 0 & 9 & $20 \%$ \\
\hline 1 & 18 & $40 \%$ \\
\hline 2 & 11 & $24 \%$ \\
\hline 3 & 6 & $13 \%$ \\
\hline 4 & 1 & $2 \%$ \\
\hline TOTAL & 45 & $100 \%$ \\
\hline
\end{tabular}

Fonte: autor da dissertação

Um número crescente de pessoas sobrevive ao câncer, entretanto uma proporção significativa deste apresentam efeitos colaterais gastrointestinais como resultado do tratamento com $\mathrm{RT}$, prejudicando sua qualidade de vida. Através de uma metodologia Cochrane WILT et al. (2008) demonstraram que as técnicas de 
radioterapia conformacional representam uma melhoria significativa em relação às técnicas de radioterapia mais antigas. O IMRT pode ser melhor que a RT-3D em termos de toxicidade gastrointestinal, mas as evidências para apoiar isso são incertas. Não foram encontradas evidências de alta qualidade para apoiar o uso de qualquer outra intervenção profilática avaliada. No entanto, evidências de algumas intervenções em potencial mostram que elas provavelmente não têm nenhum papel a desempenhar na redução da toxicidade gastrointestinal relacionada à RT. Mais ensaios clínicos randomizados são necessários para avaliar os resultados das intervenções com objetivo de minimizar esses efeitos tóxicos (WILT, T. J. et al., 2008).

Além disso, uma metanálise recente apresenta o uso de probióticos na intervenção profilática para efeitos colaterais na radioterapia. Atualmente, sua capacidade de preservar a homeostase intestinal é testada para ajudar a combater a disbiose em pacientes com câncer submetidos à quimioterapia e RT. Este trabalho mostrou três estudos independentes com espécies residentes específicas do intestino que podem potencializar o resultado positivo da imunoterapia anticâncer. Foi relatado o papel do Lactobacillus rhamnosus GG (LGG), como o modelo de probiótico mais estudado no câncer. No geral, de acordo com suas descobertas, estratégias inovadoras que integram probióticos, como LGG, com terapias anticâncer convencionais são fortemente encorajadas e podem ser indicadas para minimizar ou mesmo impedir os efeitos colaterais da RT (ZELEFSKY, M. J. et al, 2011).

A RT para o câncer de próstata evoluiu constantemente nas últimas décadas, melhorando a sobrevida livre de doenças bioquímicas. Exemplos de técnicas de RT aprimoradas são a RT guiada por imagem, a RT com intensidade modulada, a terapia volumétrica com arco modulado e a RT do corpo ablativo estereotático, o que poderia facilitar o aumento da dose. A braquiterapia é uma forma interna de RT que também se desenvolveu substancialmente. Novos dispositivos, como espaçadores retos e balões, foram desenvolvidos para poupar estruturas retais. Técnicas mais recentes, como prótons e íons de carbono, têm características intrínsecas que maximizam a dose no tumor enquanto minimizam o efeito no tecido saudável circundante, mas dados clínicos são necessários para confirmação em estudos randomizados de fase III. Além disso, fornece uma visão geral de uma importante questão de discussão no tratamento de câncer de próstata 
entre urologistas e radio-oncologistas: a comparação entre prostatectomia radical e RT. A literatura atual revela que todas as modalidades de tratamento possíveis têm a mesma taxa de cura, mas um padrão de toxicidade diferente. Recomendase propor as possíveis modalidades diferentes de tratamento, com vantagens e efeitos colaterais próprios para cada paciente, especificidades do centro de radioterapia e suas realidades socioeconômicas. Médicos e pacientes devem tomar decisões de tratamento juntos (tomada de decisão compartilhada) (GIGLIOLI, M, 2015).

Este estudo tem algumas limitações. Primeiro, foi um estudo piloto com 45 pacientes. Segundo, não foi apresentada as doses incidentes nos tecidos e órgãos alvos e em risco. Terceiro, as toxicidades agudas não foram avaliadas com base no Critério de Terminologia Comum para Eventos Adversos versão 4.0 ou no Grupo de Oncologia para Radioterapia / Organização Europeia para Pesquisa e Tratamento do Câncer (RTOG / EORTC). Sendo assim, não foi classificado quanto a graduação dos efeitos adversos e sim avaliada a presença ou ausência dos efeitos. 


\section{CONCLUSÃO}

O tratamento radioterápico do câncer de próstata na Instituição desse estudo foi associado a um amplo potencial de efeitos colaterais agudos e a incidência de efeitos agudos foi de 3 eventos de toxicidade para cada 10 consultas de pacientes.

A maioria dos pacientes $(80,0 \%)$ deste estudo apresentou algum EA. A polaciúria foi o EA mais comum (44,0\%). Houve um predomínio de EA agudos na primeira consulta $(59,1 \%)$ e na segunda e terceira foi observada uma tendência de redução nas manifestações desses $\mathrm{EA}(22,7 \%$ e $18,2 \%$, respectivamente).

A observação mais frequente foi de pelo menos um EA agudo por paciente $(40,0 \%)$ e o menos comum foi a manifestação de quatro EA concomitantemente $(2,2 \%)$. Nenhum paciente nesse estudo apresentou mais de quatro efeitos adversos agudos.

Não foi possível observar uma associação significativa das apresentações dos EA com as características sociodemográficas e clínicas nos pacientes deste estudo, exceto para etnia parda e negra que apresentou uma tendência de ter maior chance de incidência de toxidade aguda do que os pacientes brancos.

Com a realização deste trabalho foi identificada as manifestações das toxicidades agudas nos pacientes dentro da realidade socioeconômica da macrorregião assistida por esta Unidade de Oncologia. Desta forma, este estudo permitiu divulgar junto à equipe dessa unidade acerca dos eventos adversos (EA) mais frequentes para que a mesma procure melhor conduzir estes pacientes minimizando o impacto na sua qualidade de vida. Ademais, conhecer a epidemiologia destes EA melhorou a instrumentalização do médico e paciente para escolher a sua modalidade terapêutica levando em consideração as vantagens da radioterapia externa que é um procedimento indolor que não necessita de internação hospitalar, cujo efeitos adversos agudos são de fáceis tratamento quando comparados com os riscos de um procedimento invasivo como a prostatectomia. 


\section{REFERÊNCIAS}

AGENCIA SAÚDE. Brasil registra queda da taxa de mortalidade por alguns tipos de câncer. Disponível em:

<http://www2.inca.gov.br/wps/wcm/connect/agencianoticias/site/home/noticias/201 4/brasil_registra_queda_taxa_mortalidade_por_alguns_tipos_cancer>. Acesso em: 24 ago. 2015.

ALMOND, P. R. et al. AAPM's TG-51 protocol for clinical reference dosimetry of high-energy photon and electron beams. Medical Physics, v. 26, n. 9, p. 1847-1870, 1 set. 1999.

ALTMAN DG. Statistics in medical journals: developments in the 1980s. Stat Med.;10:1897-913, 1991.

AMERICAN CANCER SOCIETY. Surgery for Prostate Cancer. Disponível em: https://www.cancer.org/cancer/prostate-cancer/treating/surgery.html. Acesso em: 01 fev.2019

ANDERSON-JACKSON, L.; MCGROWDER, D. A.; ALEXANDER-LINDO, R. Prostate Specific Antigen and Gleason Score in Men with Prostate Cancer at a Private Diagnostic Radiology Centre in Western Jamaica. Asian Pacific Journal of Cancer Prevention, v. 13, n. 4, p. 1453-1456, 30 abr. 2012.

BARQAWI, A. B. et al. The value of second-opinion pathology diagnoses on prostate biopsies from patients referred for management of prostate cancer. International Journal of Clinical and Experimental Pathology, v. 4, n. 5, p. 468475, 20 jun. 2011.

BEKELMAN, J. E. et al. Outcomes After Intensity-Modulated Versus Conformal Radiotherapy in Older Men With Nonmetastatic Prostate Cancer. International Journal of Radiation Oncology`BiologyPhysics, v. 81, n. 4, p. e325e334, nov. 2011.

BOORJIAN, S. A. et al. Long-term survival after radical prostatectomy versus external-beam radiotherapy for patients with high-risk prostate cancer.

Cancer, v. 117, n. 13, p. 2883-2891, 1 jul. 2011. 
CANCER RESEARCH UK. Disponível em:

<http://www.cancerresearchuk.org/home-page>. Acesso em: 24 ago. 2015.

CITAK-ER, F. et al. Final Gleason Score Prediction Using Discriminant Analysis and Support Vector Machine Based on Preoperative Multiparametric MR Imaging of Prostate Cancer at 3T. BioMed Research International, v. 2014, p. 1-9, 2014.

DANTHAI, T. et al. Comparation of online IGRT techniques for provstate IMRT treatment: Adaptive vs repositioning correction. Medical Physics, v. 1651, p. 36, 2009.

D'AMICO, A. V. et al. Biochemical outcome after radical prostatectomy, external beam radiation therapy, or interstitial radiation therapy for clinically localized prostate cancer. JAMA, v. 280, n. 11, p. 969-974, 16 set. 1998.

GAINSBURG, D. M. et al. Intraoperative Management of Robotic-Assisted Versus Open Radical Prostatectomy. JSLS : Journal of the Society of Laparoendoscopic Surgeons, v. 14, n. 1, p. 1-5, 2010.

GIGLIOLI, M. Avaliação da distribuição da dose absorvida em radioterapia com campos irregulars e alargados. 2012. Tese (Doutoramento) - Instituto de Pesquisas Energéticas e Nucleares - IPEN-CNEN/SP, São Paulo. 130 p. Disponível em: < http://www.teses.usp.br > Acesso em : 15 outubro 2015.

HOFFMAN, R. M. et al. Mortality After Radical Prostatectomy or External Beam Radiotherapy for Localized Prostate Cancer. JNCI Journal of the National Cancer Institute, v. 105, n. 10, p. 711-718, 15 maio 2013.

HU, J. et al. Neo-adjuvant hormone therapy for non-metastatic prostate cancer: a systematic review and meta-analysis of 5,194 patients. World Journal of Surgical Oncology, v. 13, n. 1, p. 73, 2015.

HUMMEL, S. et al. Intensity-modulated radiotherapy for the treatment of prostate cancer: a systematic review and economic evaluation. Health Technology Assessment, v. 14, n. 47, out. 2010. 
INCA. ATLAS DE MORTALIDADE POR CÂNCER NO BRASIL, 1979-1999.

Disponível em: <https://www.inca.gov.br/atlas>. Acesso em: 24 ago. 2015.

INCA. Instituto Nacional de Câncer - Estimativa 2018. Disponível em:

<http://www.inca.gov.br/estimativa/2018>. Acesso em: 24 ago. 2018.

LIN, P.-H.; ARONSON, W.; FREEDLAND, S. J. Nutrition, dietary interventions and prostate cancer: the latest evidence. BMC Medicine, v. 13, n. 1, p. 3, 2015.

LUO, H.-C. et al. Intensity-modulated Radiotherapy Combined with Endocrine Therapy for Intermediate and Advanced Prostate Cancer: Long-term Outcome of Chinese Patients. Asian Pacific Journal of Cancer Prevention, v. 14, n. 8, p. 4711-4715, 30 ago. 2013.

MATSUDA, T.; MATSUDA, A. Time Trends in Prostate Cancer Mortality Between 1950 and 2008 in Japan, the USA and Europe Based on the WHO Mortality Database. Japanese Journal of Clinical Oncology, v. 41, n. 12, p. 13891389, 1 dez. 2011.

MILECKI, T. et al. Review. The use of luteinizing hormonereleasing hormone analogues is still an indispensable element of therapy in castrate-resistant prostate cancer. Współczesna Onkologia, v. 2, p. 85-89, 2014.

MOON, S. J.; PARK, S. Y.; LEE, T. Y. Predictive Factors of Gleason Score Upgrading in Localized and Locally Advanced Prostate Cancer Diagnosed by Prostate Biopsy. Korean Journal of Urology, v. 51, n. 10, p. 677, 2010.

NATIONAL CANCER INSTITUTE. Cancer Therapy Evaluation Program CTEP. Disponível em:

$<$ http://ctep.cancer.gov/protocolDevelopment/electronic_applications/ctc.htm\#ctc_ archive>. Acesso em: 4 set. 2015.

PATE; KLEIN. Risk factors for prostate cancer. Disponível em: <http://www.ncbi.nlm.nih.gov/pubmed/19198622>. Acesso em: 24 ago. 2015.

PEREZ; BRADY'S. Perez and Brady's principles and practice of radiation oncology. 6th. ed. [s.l.] Edward C. Halperin, 2013. 
POLI, M. E. R. Definição do volume de planejamento do alvo (ptv) e seu efeito na radioterapia. 2007. Tese (Doutoramento) - Instituto de Pesquisas Energéticas e Nucleares - IPEN-CNEN/SP, São Paulo. 371 p. Disponível em: < http://www.teses.usp.br > Acesso em : 15 outubro 2015.

REESE, A. C. et al. The quantitative Gleason score improves prostate cancer risk assessment: Quantitative Gleason Score. Cancer, v. 118, n. 24, p. 60466054, 15 dez. 2012.

$\mathrm{ROACH}, \mathrm{M}$. Current trends for the use of androgen deprivation therapy in conjunction with radiotherapy for patients with unfavorable intermediaterisk, high-risk, localized, and locally advanced prostate cancer: ADT and Radiotherapy for Prostate Cancer. Cancer, v. 120, n. 11, p. 1620-1629, 1 jun. 2014.

ROSTELATO, Maria E.C.M.. Estudo e desenvolvimento de uma nova metodologia para confecção de sementes de iodo-125 para aplicação em braquiterapia. 2005. Tese (Doutoramento) - Instituto de Pesquisas Energeticas e Nucleares - IPEN/CNEN-SP, Sao Paulo, Brasil

WALSH, A. L. et al. Digital rectal examination in primary care is important for early detection of prostate cancer: a retrospective cohort analysis study. British Journal of General Practice, v. 64, n. 629, p. e783-e787, 1 dez. 2014.

WHO. GLOBOCAN 2012: Estimated Cancer Incidence, Mortality and Prevalence Worldwide in 2012. Disponível em:

$<$ http://globocan.iarc.fr/Pages/fact_sheets_cancer.aspx>. Acesso em: 24 ago. 2015.

WILT, T. J. et al. Systematic review: comparative effectiveness and harms of treatments for clinically localized prostate cancer. Annals of internal medicine, v. 148, n. 6, p. 435-448, 2008.

ZELEFSKY, M. J. et al. Comparison of Tumor Control and Toxicity Outcomes of High Dose Intensity-Modulated Radiotherapy and Brachytherapy for Patients with Favorable Risk Prostate Cancer. Urology, v. 77, n. 4, p. 986-990, abr. 2011. 
ZHOU, E. H. et al. Radiation Therapy and Survival in Prostate Cancer Patients

- A Population-based Study. International journal of radiation oncology, biology, physics, v. 7 


\section{GLOSSÁRIO}

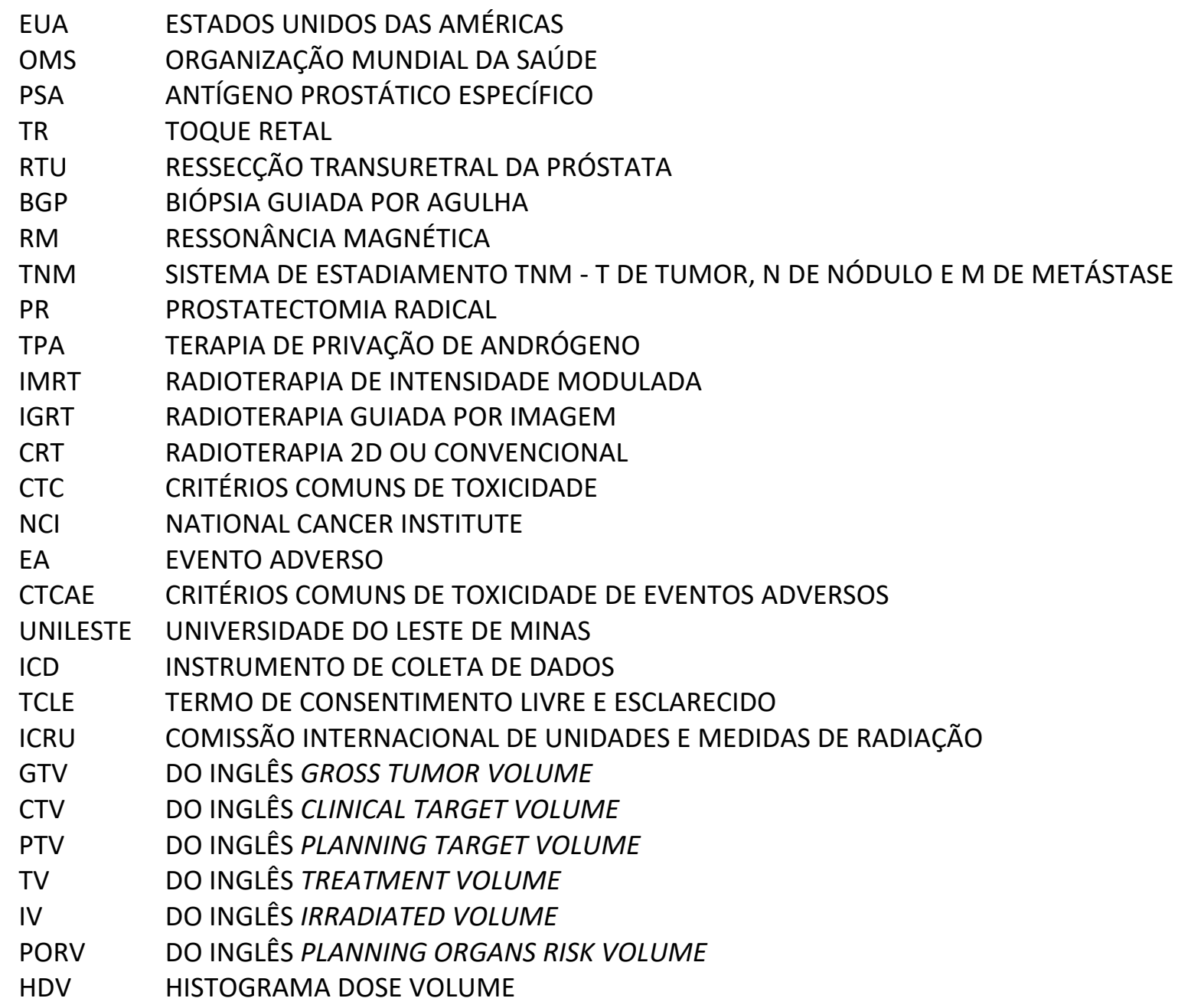




\section{ANEXOS}

ANEXO - 1 Termo de Consentimento livre e Esclarecido (TCLE)

ANEXO - 2 Instrumento de Coleta de Dados (ICD)

ANEXO - 3 Toxicidade aguda da radioterapia baseada na escala de graduação de RTOG

ANEXO - 4 Termo de aprovação pelo Comite de Ética em Pesuisa 


\title{
ANEXO - 1 Termo de Consentimento livre e Esclarecido (TCLE)
}

\author{
壮 Unileste \\ Comitê de Ética em Pesquisa \\ TERMO DE CONSENTIMENTO LIVRE E ESCLARECIDO (TCLE) \\ DESTINADO AOS PARTICIPANTES DA PESQUISA
}

Titulo da pesquisa: Avaliação dos efeitos colaterais agudos em pacientes com câncer de próstata tratados com radioterapia conformacional em um Hospital no Leste de Minas

Pesquisador (a) responsável: Higor Souza Carlech

Telefone(s) de contato: (31) 98806-3260

Email:higorcarlech12@hotmail.com

Período total de duração da pesquisa: 01/03/2017 a 31/05/2017

1. Eu, estou sendo convidado(a) a participar de uma pesquisa coordenada pelo pesquisador médico, Dr. Higor Souza Carlech.

2. O propósito da pesquisa é avaliar a sua saúde durante o período de 3 (três) meses do seu tratamento com radioterapia. Esse tratamento é necessário para combater o seu câncer de próstata. A sua participação nessa pesquisa será muito importante para podermos conhecer a sua saúde, o que o senhor irá sentir durante o tratamento. Junto com o senhor teremos um total de 171 pacientes para que o resultado desse trabalho possa ser aproveitado pela equipe médica com o objetivo de prevenir e tratar possíveis sintomas que prejudicam a vida do paciente durante o seu tratamento de radioterapia. $O$ resultado desse trabalho também irá servir para melhor orientar, no futuro, os pacientes que irão passar pelo mesmo protocolo de tratamento.

3. E como será a sua participação? O senhor irá responder ao seu médico, durante consulta de rotina na Unidade de Oncologia, perguntas pessoais como idade, educação e o seu estado de saúde atual. A sua saúde será acompanhada e registrada durante um período de 3 (três) meses para essa pesquisa. Sempre que sentir dor ao fazer xixi, ou começar a fazer muitas vezes ao dia, sentir dor de barriga, ou cólica, não conseguir segurar o xix, sentir dor ao fazer cocô, ter diarréia, ver sangue no xixi ou no cocô ou sentir-se muito cansado, mesmo após descansar, ou outro sintoma que achar importante deverá se apresentar à Unidade de Oncologia ou ao Pronto Socorro do Hospital Marcio Cunha para que possa ser avaliado e tratado. Deve lembrar-se de comunicar ao médico que te atender que faz parte de uma pesquisa da Unidade de Oncologia do Dr. Higor Souza Carlech. Com isso os seus dados serão 
incluídos na pesquisa. Além disso, deve seguir o protocolo apresentado na Unidade de Oncologia, procurando comparecer a todas as sessões de radioterapia e consultas que the encaminharem;

4. Participar dessa pesquisa tem algum risco? Essa pesquisa possui o risco de expor os seus dados para estranhos. Além disso, sempre que tiver algum dos sintomas relatados acima deverá se apresentar aos lugares designados para que seja avaliado e tratado. As avaliações a que será submetido também apresentam riscos do próprio procedimento como se sentir envergonhado pelo exame de toque retal, dor e hematoma no local de retirada de sangue, além de risco relacionados aos exames de imagem como a tomografia. É importante que o senhor saiba que passaria por todos esses exames estando ou não neste estudo, pois este estudo não muda em nada o seu tratamento apenas permite que os seus dados e sintomas possam ser analisados e comparados com outros casos para publicação dos resultados, mas seu anonimato será garantido. Pode também se sentir impaciente e/ou insatisfeito por ter que ser acompanhado por uma equipe de pesquisadores, interrogando sobre seu estado, durante esse momento delicado de tratamento. Entretanto, todos esses riscos da pesquisa serão minimizados ao garantirmos o compromisso de todos os participantes da pesquisa em serem gentis e cuidadosos ao examinarem e conversarem com o senhor, em qualquer etapa da pesquisa, todos os questionários e entrevistas serão realizados de forma sigilosa e isolada de público, todos os seus dados serão mantidos com códigos impossibilitando que identifiquem o senhor. O que for guardado no computador será bloqueado por senha e quando armazenado em folhas elas serão mantidas em pastas e guardadas em armário com chave. Todos os profissionais de saúde que realizarão os procedimentos são profissionais treinados e experientes. Junto a essa equipe temos uma psicóloga e uma assistente social que estão disponíveis mediante agenda a te atender quando sentir necessidade de um apoio emocional, além disso, qualquer dúvida a cerca da pesquisa pode ser tirada com o pesquisador responsável no telefone apresentado acima;

5. Os possíveis benefícios de sua participação na pesquisa serão contribuir com dados a cerca das complicações dos tratamentos com radioterapia do câncer de próstata que irão preparar melhor os pacientes e os profissionais de saúde para conduzir de forma mais assertiva o doente melhorando a sua qualidade de vida apesar do tratamento, ademais, durante o seu tratamento terá todo o apoio da equipe de pesquisadores para tirar dúvidas além de ser atendido por profissionais competentes e interessados em conhecer a sua situação e promover o seu tratamento;

6. Sua participação na pesquisa não acarretará nenhum preconceito, discriminação ou desigualdade social, mesmo que decida não participar da pesquisa terá acesso aos mesmos profissionais e aos mesmos procedimentos de que se participasse uma vez que essa pesquisa não interfere na conduta prevista e sim deseja acompanhar em tempo real reunindo o máximo de informações necessárias; 
7. Os resultados deste estudo podem ser publicados, mas seu nome ou identificação não serão revelados;

8. Não haverá remuneração ou ajuda de custo (ressarcimento) pela sua participação;

9. Quaisquer dúvidas que você tiver em relação à pesquisa ou à sua participação, antes ou depois do consentimento, serão respondidas pelo pesquisador Higor Souza Carlech;

10. Esta pesquisa foi aprovada sob registro de Protocolo $n^{\circ}$ Ofício pelo Comitê de Ética em pesquisa em Seres Humanos do Unileste que funciona no Bloco U, sala 107, Campus I do Centro Universitário do Leste de Minas Gerais, localizado à Avenida Presidente Tancredo Neves, 3500 - Bairro Universitário - Coronel Fabriciano - MG - CEP 35170-056 - Telefone: 38465687. Assim, este termo está de acordo com a Resolução 466 do Conselho Nacional de Saúde, de 12 de dezembro de 2012, para proteger os direitos dos seres humanos em pesquisas. Qualquer dúvida quanto aos seus direitos como participante em pesquisas, ou se sentir que foi colocado em riscos não previstos, você poderá contatar o Comitê de Ética em Pesquisa para esclarecimentos;

$\mathrm{Li}$ as informações acima, recebi explicações sobre a natureza, riscos e benefícios do projeto. Comprometo-me a colaborar voluntariamente e compreendo que posso retirar meu consentimento e interrompê-lo a qualquer momento, sem penalidade ou perda de benefício.

Ao assinar este termo, não estou desistindo de quaisquer direitos meus. Uma cópia deste termo me foi dada.

Assinatura do participante Data

Documento:

Assinatura do pesquisador Data

Documento: 
ANEXO - 2 Instrumento de Coleta de Dados (ICD)

FICHA NÚMERO:

\section{INSTRUMENTO DE COLETA DE DADOS}

\section{ANEXO 1: DADOS PESSOAIS}

1. - Entrevistador fala: "Gostaria de fazer algumas perguntas sobre o senhor":

1.1. Qual a sua idade? anos

1.2. Qual a sua data de nascimento?

1.3. Como você considera a sua cor de pele:

\begin{tabular}{|l|l|l|l|l|l|l|l|l|l|}
\hline BRANCA & & AMARELA & & PARDA & & PRETA & & INDÍGENA & \\
\hline
\end{tabular}

1.4. Qual foi a última série completa que o senhor frequentou na escola?

1.5. Qual é a sua profissão?

1.6. Atualmente o senhor é?

\begin{tabular}{|l|l|l|l|l|l|l|l|l|l|}
\hline SOLTEIRO & & CASADO & & VIVE JUNTO & & SEPARADO & & VIÚVO & \\
\hline
\end{tabular}

1.7. O senhor apresenta algum desses sintomas?

\begin{tabular}{|l|l|l|l|}
\hline SINTOMA & SIM & NÃO & NÃO \\
\hline a. urina muitas vezes ao dia & & & \\
\hline b. dor ao fazer xixi & & & \\
\hline c. cólica & & & \\
\hline d. não consegue segurar a urina & & & \\
\hline e. não consegue fazer todo o xixi & & & \\
\hline f. dor ao fazer cocô & & & \\
\hline g. diarreia & & & \\
\hline h. tem hemorragia, sangramento & & & \\
\hline i. fadiga, cansaço que não passa & & & \\
\hline j. náusea ou vômito & & & \\
\hline
\end{tabular}

"Gostaria de agradecer-Ihe pela atenção e pelo tempo dedicado a responder às perguntas." 


\section{ANEXO - 3 Toxicidade aguda da radioterapia baseada na escala de graduação de RTOG}

\begin{tabular}{|c|c|c|c|c|c|}
\hline Toxicidade & Grau 0 & Grau 1 & Grau 2 & Grau 3 & Grau 4 \\
\hline $\begin{array}{l}\text { Gastrintestinal baixo } \\
\text { incluindo pétris }\end{array}$ & Sem alteraçốes & $\begin{array}{l}\text { Aumento na Frequência ou } \\
\text { caraderística do hábito intestinal, } \\
\text { nẫo requer medicaçấo. Desconforto } \\
\text { retal que nẫo requer analgésico. }\end{array}$ & $\begin{array}{l}\text { Diarreia que requer } \\
\text { medicaçốes. Dor retal ou } \\
\text { abdominal que requer } \\
\text { analgésico. }\end{array}$ & \begin{tabular}{|l|} 
Diarreia que requer suporte \\
parenteral. Grande quantidade de \\
muco ou sangue requer fralda. \\
Distensẫo de alça intestinal (através \\
de $\mathrm{RX}$ )
\end{tabular} & $\begin{array}{l}\text { Obstruçẫo aguda ou subaguda, } \\
\text { fístula ou perfuraçẫo; } \\
\text { Sangramento gastrintestinal que } \\
\text { requer trarsfusấo. Dor abdominal } \\
\text { ou tenesmo (sondagem ou } \\
\text { derivaçăo para descompress ấo) }\end{array}$ \\
\hline Gastrintestinal alto & Sem alterações & $\begin{array}{l}\text { Anorexia com perda do peso } \leq \text { do } \\
\text { que } 5 \% \text {. Náus ea que nấo requer } \\
\text { antiemético. Desconforto } \\
\text { abdominal que nẫo requer } \\
\text { medicação. }\end{array}$ & $\begin{array}{l}\text { Anorexia com perda de peso } \\
\leq \text { a } 15 \% \text {. Náus ea e ou } \\
\text { vônito que requer } \\
\text { antiemético. Dor abdominal } \\
\text { que requer analgésico. }\end{array}$ & $\begin{array}{l}\text { Anorexia com perda de peso > que } \\
15 \% \text {, ou necessidade de sonda para } \\
\text { alimentaçẫo. Náusea e } / \text { ou vônito } \\
\text { que requer sonda ou suporte } \\
\text { parenteral. Dor abdominal severa } \\
\text { mesmo medicada. Hematemise ou } \\
\text { melena. Distensão abdominal }\end{array}$ & $\begin{array}{l}\text { Obstrução aguda ou subaguda } \\
\text { de íleo, perfuração, } \\
\text { sangramento gastrintestinal que } \\
\text { requer transfusăo. Dor abdominal } \\
\text { que requer sonda para } \\
\text { descompressão ou derivaçắo } \\
\text { intestinal. }\end{array}$ \\
\hline Geniturinária & Sem alteraçốes & $\begin{array}{l}\text { Frequência urinária duas vezes } \\
\text { maior que o hábito } \\
\text { normal.Disúria ou urgência que } \\
\text { não requer tratarnento }\end{array}$ & $\begin{array}{l}\text { Frequência urinária ou } \\
\text { noctúria em intervalo maior } \\
\text { que uma hora. Disúria } \\
\text { espasmo vesical que requer } \\
\text { anestésico local (pyridium). }\end{array}$ & $\begin{array}{l}\text { Frequência com urgência e nuctúria } \\
\text { a cada hora ou menos / disúria, dor } \\
\text { em pélvis, ou espasmo vesical que } \\
\text { requer regular frequente narcótico. } \\
\text { Hernatúria franca. }\end{array}$ & $\begin{array}{l}\text { Hematúria que requer } \\
\text { transfusẫo. Obstruçẫo aguda de } \\
\text { bexiga devido a } \\
\text { coágulos. Ulceraçăo ou necrose }\end{array}$ \\
\hline Demnatológica & Sem alteraçỗes & $\begin{array}{l}\text { Eritema folicular fraco ou } \\
\text { apagado, epilaçẫo, descarnaçã̃o } \\
\text { seca, diminuiçẫo da sudorese. }\end{array}$ & $\begin{array}{l}\text { Eritema brando ou claro, } \\
\text { descarnação úmida em } \\
\text { placas, edema moderado. }\end{array}$ & $\begin{array}{l}\text { Descarnação úmida confluente, } \\
\text { além das dobras da pele, ederna em } \\
\text { "casca de laranja" }\end{array}$ & Ulceração, Hemorragia, necrose. \\
\hline $\begin{array}{l}\text { Hernatológica } \\
\text { WBC }(<1000)\end{array}$ & $\geq 4,0$ & $3,0-<4,0$ & $2,0-<3,0$ & $1,0-<2,0$ & $<1,0$ \\
\hline Plaquetas $(\times 1000)$ & $>100$ & $75-<100$ & $50-<75$ & $25-<50$ & $<25$ ou sangramento espontâneo \\
\hline Neutrófilos & $\geq 1,9$ & $1,5-<1,9$ & $1,0-<1,5$ & $0,5-<1,0$ & $<0,5$ ou sepsis \\
\hline Hemoglobina (GM\%) & $>11$ & $11-9,5$ & $9,5-7,5$ & $<7,5-5,0$ & - \\
\hline Hematócrito $(\%)$ & $\geq 32$ & $28-<32$ & $<28$ & Requer transfusão & - \\
\hline
\end{tabular}




\section{ANEXO - 4 Termo de Aprovação pelo Comite de Ética em Pesuisa}

\section{Unileste}

Comitê de Ética em Pesquisa
CENTRO UNIVERSITÁRIO DO

LESTE DE MINAS GERAIS/

UNILESTE - UNIÃO

Continuação do Parecer: 1.874 .166

\section{PARECER CONSUBSTANCIADO DO CEP}

\section{DADOS DO PROJETO DE PESQUISA}

Título da Pesquisa: AVALIAÇÃO DOS EFEITOS COLATERAIS AGUDOS EM PACIENTES COM CÂNCER DE PRÓSTATA TRATADOS COM RADIOTERAPIA CONFORMACIONAL

Pesquisador: Higor Souza Carlech

Área Temática:

Versão: 2

CAAE: 56573816.2 .0000 .5095

Instituição Proponente:União Educacional do Vale do Aço Ltda

Patrocinador Principal: Financiamento Próprio

\section{DADOS DO PARECER}

\section{Número do Parecer: 1.874.166}

\section{Apresentação do Projeto:}

Este trabalho objetiva avaliar a toxicidade aguda em pacientes com câncer de próstata tratados com radioterapia conformacional (3D) em uma Unidade de Oncologia do Leste de Minas de forma padronizada com o intuito de fornecer mais subsídios para a escolha do melhor tratamento. Será realizado, portanto um estudo prospectivo, observacional, longitudinal, tipo Coorte. Todos os pacientes elegíveis para o tratamento com radioterapia, admitidos no período de um ano, entre fevereiro de 2017 e fevereiro de 2018, serão incluídos na pesquisa. Através de uma amostragem não probabilística, de conveniência, pretende-se atingir um máximo de 60 pacientes ao todo. Os 
pacientes incluídos na pesquisa serão acompanhados desde o início do tratamento até o período de três meses. A pesquisa com o paciente será dividida em três fases conforme o tratamento radioterápico preconizado pela instituição.

\section{Objetivo da Pesquisa:}

Objetivo Primário:

Avaliar a toxicidade aguda em pacientes com câncer de próstata tratados com radioterapia conformacional (3D) em uma Unidade de Oncologia do Leste de Minas.

Objetivo Secundário:

- Traçar o perfil clínico dos pacientes com câncer de próstata que iniciaram o tratamento com radioterapia no período de Março de 2016 a Fevereiro de 2017.

- Acompanhar os pacientes incluídos no estudo durante o período de 3 meses com respeito a manifestaçõesde efeitos colaterais agudos à radioterapia.

- Correlacionar os efeitos colaterais com o perfil clínico de cada paciente.

- Quantificar a dose de radioterapia incidente no reto e na bexiga durante o tratamento e correlacionar comos efeitos colaterais manifestados.

- Comparar o resultado obtido com dados da literatura a cerca dos efeitos colaterais agudos esperados.

\section{Avaliação dos Riscos e Benefícios:}

Os pesquisadores anunciaram a avaliação dos riscos, bem como os benefícios. Os riscos desse projeto são riscos psicossociais, por ser um estudo observacional, não existirá nenhuma alteração da conduta clínica do paciente, expondo-o portanto à riscos relacionados à sua saúde. Entretanto, existe o risco de exposição da imagem e dados do paciente que serão minimizados através do armazenamento do instrumento de coleta de dados em armário com chaves, sob a guarda exclusiva dos membros da equipe, os dados que irão para o computador para análise serão de manejo exclusivo do pesquisador principal e o acesso ao computador será limitado por uso de senha. Na divulgação dos dados em meio científico, como relatório final e artigo científico, em nenhum momento será utilizado nome ou inicial do paciente, nem nenhuma informação pessoal que permita a possibilidade de identificação do mesmo, garantido com essas estratégias descritas, o sigilo e o anonimato dos pacientes. Ainda apresenta como risco essa pesquisa as expectativas e ansiedades que os pacientes podem ter e desenvolver, respectivamente, uma vez que sejam incluídos no estudo, relacionadas à sua condição de saúde, podem ficar receosos de terem muitos efeitos colaterais, pelo enfoque que o estudo dá ou se sentirem desconfortáveis por terem que procurar a unidade de oncologia para tratamento e registro dos efeitos assim que eles se manifestarem, podem achar que estarão recebendo algum tratamento diferente, melhor ou 
pior, por estarem no estudo, enfim todas esses sentimentos serão amenizados ao transmitir ao paciente de forma bem clara e abrangente a proposta do estudo observacional, a importância da adesão deles ao tratamento para a eficiência do tratamento. Preveem benefícios como enriquecer a literatura com uma pesquisa quantitativa e qualitativa a cerca da toxicidade do tratamento do câncer de próstata com radioterapia conformacional, de forma padronizada, auxiliando na comparação entre os diversos tratamentos disponíveis, permitindo ainda a uniformização da linguagem utilizada. De forma particular buscam melhorar a compreensão do paciente a cerca dos eventos adversos que podem vir a desenvolver em decorrência do tratamento.

\section{Comentários e Considerações sobre a Pesquisa:}

Reafirmamos a relevância deste estudo, de forma especial por trata-se de um problema com forte repercussão na saúde pública. A carta resposta emanada pelos pesquisadores veio esclarecendo e modificando as alterações já solicitadas em outra avaliação do projeto.

\section{Considerações sobre os Termos de apresentação obrigatória:}

Todos os termos foram apresentados.

\section{Recomendações:}

O projeto postado na Plataforma Brasil apresenta um dado que está oscilando no período para coleta de dados, ora de setembro de 2016 a setembro de 2017, ora em fevereiro de 2017 a fevereiro de 2018.

\section{Conclusões ou Pendências e Lista de Inadequações:}

Não há pendências éticas.

\section{Considerações Finais a critério do CEP:}

Conforme a Resolução 466/12, do Conselho Nacional de Saúde, os CEP's são responsáveis pela avaliação e acompanhamento dos aspectos éticos de todas as pesquisas envolvendo seres humanos. Portanto, é atribuição do CEP "acompanhar o desenvolvimento dos projetos, por meio de relatórios semestrais dos pesquisadores e de outras estratégias de monitoramento, de acordo com o risco inerente à pesquisa" (X.1 3 b).

O pesquisador deverá então encaminhar ao CEP/Unileste, através da plataforma Brasil, o formulário de acompanhamento (que pode ser acessado pelo link http://www.unilestemg.br/comite-de-etica) preenchido, a cada seis meses, até no máximo 45 dias após este prazo, para que o CEP possa acompanhar o desenvolvimento do mesmo. 
De acordo com o regimento deste CEP, findo este prazo ficará vetado à apreciação de novo

\begin{tabular}{|c|c|c|c|c|}
\hline Tipo Documento & Arquivo & Postagem & Autor & Situação \\
\hline $\begin{array}{l}\text { Informações } \\
\text { Básicas do Projeto }\end{array}$ & $\begin{array}{l}\text { PB_INFORMAÇÕES_BÁSICAS_DO_P } \\
\text { ROJETO_706401.pdf }\end{array}$ & $\begin{array}{c}14 / 11 / 2016 \\
18: 18: 41\end{array}$ & & Aceito \\
\hline Outros & CARTARESPOSTA.pdf & $\begin{array}{c}14 / 11 / 2016 \\
18: 18: 11\end{array}$ & $\begin{array}{l}\text { Ana Carolina Vale } \\
\text { Campos Lisbôa }\end{array}$ & Aceito \\
\hline $\begin{array}{l}\text { Projeto Detalhado } \\
\text { / } \\
\text { Brochura } \\
\text { Investigador }\end{array}$ & Projeto.pdf & $\begin{array}{c}14 / 11 / 2016 \\
18: 17: 38\end{array}$ & $\begin{array}{l}\text { Ana Carolina Vale } \\
\text { Campos Lisbôa }\end{array}$ & Aceito \\
\hline Outros & lattes_Higor.pdf & $\begin{array}{c}31 / 05 / 2016 \\
15: 57: 07\end{array}$ & $\begin{array}{l}\text { Sâmela de Barros } \\
\text { Castro Félix }\end{array}$ & Aceito \\
\hline Outros & CARTAAPRESENTACAO.jpg & $\begin{array}{l}02 / 05 / 2016 \\
21: 26: 45\end{array}$ & $\begin{array}{l}\text { Ana Carolina Vale } \\
\text { Campos Lisbôa }\end{array}$ & Aceito \\
\hline Folha de Rosto & FOLHADEROSTOASSINADA.pdf & $\begin{array}{l}02 / 05 / 2016 \\
21: 24: 17\end{array}$ & $\begin{array}{l}\text { Ana Carolina Vale } \\
\text { Campos Lisbôa }\end{array}$ & Aceito \\
\hline Outros & CartaEncaminhamentoHigorHMC.pdf & $\begin{array}{c}02 / 05 / 2016 \\
21: 20: 49 \\
\end{array}$ & $\begin{array}{l}\text { Ana Carolina Vale } \\
\text { Campos Lisbôa }\end{array}$ & Aceito \\
\hline Outros & CARTAENCAMINAHMENTO.jpg & $\begin{array}{c}02 / 05 / 2016 \\
21: 20: 17 \\
\end{array}$ & $\begin{array}{l}\text { Ana Carolina Vale } \\
\text { Campos Lisbôa }\end{array}$ & Aceito \\
\hline Outros & TRLUCIANO.jpg & $\begin{array}{c}02 / 05 / 2016 \\
21: 19: 00 \\
\end{array}$ & $\begin{array}{l}\text { Ana Carolina Vale } \\
\text { Campos Lisbôa }\end{array}$ & Aceito \\
\hline Outros & TRANACAROLINA.jpg & $\begin{array}{c}02 / 05 / 2016 \\
21: 18: 29 \\
\end{array}$ & $\begin{array}{l}\text { Ana Carolina Vale } \\
\text { Campos Lisbôa }\end{array}$ & Aceito \\
\hline Outros & TR_MARIAELISA.jpg & $\begin{array}{c}02 / 05 / 2016 \\
21: 17: 31 \\
\end{array}$ & $\begin{array}{l}\text { Ana Carolina Vale } \\
\text { Campos Lisbôa }\end{array}$ & Aceito \\
\hline Outros & TR_HIGOR.jpg & $\begin{array}{c}02 / 05 / 2016 \\
21: 16: 21 \\
\end{array}$ & $\begin{array}{l}\text { Ana Carolina Vale } \\
\text { Campos Lisbôa }\end{array}$ & Aceito \\
\hline Outros & ICD.pdf & $\begin{array}{c}28 / 04 / 2016 \\
17: 14: 03 \\
\end{array}$ & $\begin{array}{l}\text { Ana Carolina Vale } \\
\text { Campos Lisbôa }\end{array}$ & Aceito \\
\hline $\begin{array}{l}\text { TCLE / Termos de } \\
\text { Assentimento / } \\
\text { Justificativa de } \\
\text { Ausência }\end{array}$ & TCLE.pdf & $\begin{array}{c}28 / 04 / 2016 \\
17: 13: 20\end{array}$ & $\begin{array}{l}\text { Ana Carolina Vale } \\
\text { Campos Lisbôa }\end{array}$ & Aceito \\
\hline
\end{tabular}

protocolo de pesquisa ao CEP/Unileste. Tão logo o pesquisador regularize a sua situação junto ao

Comitê este está apto a submissão de novas propostas.

Ao término da pesquisa, o responsável deverá enviar o protocolo, o mais rápido possível, dentro dos prazos informados acima, bem como anexar junto o relatório e/ou artigo referente ao projeto, na plataforma Brasil.

Todas as publicações também deverão ser informadas, mesmo após o envio do relatório final. Agradecemos a atenção e colocamo-nos a inteira disposição para quaisquer esclarecimentos.

Este parecer foi elaborado baseado nos documentos abaixo relacionados: 


\section{Situação do Parecer:}

Aprovado

Necessita Apreciação da CONEP:

Não

CORONEL FABRICIANO, 19 de Dezembro de 2016

Assinado por:

Tania Gonçalves dos Santos

(Coordenador)

p Endereço: Av.Presidente Tancredo Neves no 3500, Bloco U, sala 107.

Bairro: Bairro Universitário

CEP: $\quad 35.170-056$

UF: MG Município: CORONEL FABRICIANO

Telefone: (31)3846-568-7 Fax: (31)3846-5687 E-mail: etica@unilestemg.bde 